\title{
Modeling of human factor Va inactivation by activated protein $\mathrm{C}$
}

\author{
Maria Cristina Bravo', Thomas Orfeo ${ }^{2}$, Kenneth G Mann² and Stephen J Everse ${ }^{1,3^{*}}$
}

\begin{abstract}
Background: Because understanding of the inventory, connectivity and dynamics of the components characterizing the process of coagulation is relatively mature, it has become an attractive target for physiochemical modeling. Such models can potentially improve the design of therapeutics. The prothrombinase complex (composed of the protease factor (F)Xa and its cofactor FVa) plays a central role in this network as the main producer of thrombin, which catalyses both the activation of platelets and the conversion of fibrinogen to fibrin, the main substances of a clot. A key negative feedback loop that prevents clot propagation beyond the site of injury is the thrombin-dependent generation of activated protein $C(A P C)$, an enzyme that inactivates FVa, thus neutralizing the prothrombinase complex. APC inactivation of FVa is complex, involving the production of partially active intermediates and "protection" of FVa from APC by both FXa and prothrombin. An empirically validated mathematical model of this process would be useful in advancing the predictive capacity of comprehensive models of coagulation.
\end{abstract}

Results: A model of human APC inactivation of prothrombinase was constructed in a stepwise fashion by analyzing time courses of FVa inactivation in empirical reaction systems with increasing number of interacting components and generating corresponding model constructs of each reaction system. Reaction mechanisms, rate constants and equilibrium constants informing these model constructs were initially derived from various research groups reporting on APC inactivation of FVa in isolation, or in the presence of FXa or prothrombin. Model predictions were assessed against empirical data measuring the appearance and disappearance of multiple FVa degradation intermediates as well as prothrombinase activity changes, with plasma proteins derived from multiple preparations. Our work integrates previously published findings and through the cooperative analysis of in vitro experiments and mathematical constructs we are able to produce a final validated model that includes 24 chemical reactions and interactions with 14 unique rate constants which describe the flux in concentrations of 24 species.

Conclusion: This study highlights the complexity of the inactivation process and provides a module of equations describing the Protein C pathway that can be integrated into existing comprehensive mathematical models describing tissue factor initiated coagulation.

Keywords: Coagulation, Factor Va, Activated protein C, Prothrombinase, Prothrombin, Factor Xa, Mathematical modeling

\footnotetext{
* Correspondence: Stephen.Everse@uvm.edu

${ }^{1}$ Cell and Molecular Biology Program, University of Vermont, 89 Beaumont

Ave, Burlington VT 05405, USA

${ }^{3}$ Department of Biochemistry, University of Vermont, 89 Beaumont Ave.,

Given B418, Burlington VT 05405, USA

Full list of author information is available at the end of the article
} 


\section{Background}

One of the critical events in blood coagulation is the conversion of large amounts of the zymogen prothrombin to the enzyme thrombin by the enzymatic complex prothrombinase. The prothrombinase complex is formed by the non-covalent interaction between the enzyme factor $\mathrm{Xa}$ (FXa) and the non-enzymatic cofactor factor $\mathrm{Va}(\mathrm{FVa})$ on a phospholipid surface in the presence of calcium [1-3]. The procofactor, factor V, is activated by thrombin to generate a calciumassociated two chain molecule, composed of a heavy chain $\left(\mathrm{FVa}^{\mathrm{HC}}\right)$ and light chain $\left(\mathrm{FVa}^{\mathrm{LC}}\right)$ (Figure 1) $[4,5]$. The prothrombinase complex increases thrombin generation over FXa alone by 5 orders of magnitude [2]. The explosive burst in prothrombin conversion is essential to rapidly form a stable fibrin clot in response to a vascular injury. The fibrin clot is formed when thrombin cleaves fibrinogen to form an insoluble polymer network [6,7]. This fibrin network becomes cross-linked and stabilized by factor XIIIa which also traps platelets and red blood cells sealing the wound [7-9].

It is critical that once a procoagulant response to vascular injury has been initiated that an appropriate anticoagulant response is concurrently mounted. As such, the components of the prothrombinase complex are targets of multiple regulatory mechanisms to terminate the production of thrombin. First, FXa availability is regulated by formation of inhibition complexes with antithrombin (AT), $\alpha_{1}$-antitrypsin, and tissue factor pathway inhibitor (TFPI) $[10,11]$. The cofactor, FVa, is a target for degradation by activated protein $\mathrm{C}$ (APC). APC, a serine protease derived from its plasma precursor protein $\mathrm{C}(\mathrm{PC})$ in a thrombin dependent process [12], plays a critical role in inactivating the non-enzymatic cofactor components of both the prothrombinase and the intrinsic tenase complexes, factors Va and VIIIa, respectively [13-15]. Additional key components of the PC pathway include: thrombomodulin and endothelial protein $\mathrm{C}$ receptor (EPCR) which contribute to APC formation [16]; protein $\mathrm{S}$ which functions as a cofactor enhancing APC efficacy [17]; and protein $\mathrm{C}$ inhibitor, a suppressor of APC formation [18,19].

An increased risk of thrombotic disease has been associated with partial deficiencies or loss of function mutations in the PC pathway, including deficiencies in PC, its cofactor protein $\mathrm{S}$, or proteins involved in the activation of PC [20]. The most prevalent defect in the PC pathway is a result of a genetic mutation in FV that renders the cofactor resistant to APC inactivation [21]. This resistance to APC was first characterized by Dahlbäck and coworkers [21] and derives from a mutation at one of the APC inactivation sites $\left(\mathrm{Arg}^{506} \rightarrow \mathrm{Gl}^{506}\right)$ on FV/FVa rendering it resistant to APC cleavage [22].

APC catalyzed inactivation of FVa cofactor activity is a complex, membrane dependent process involving cleavage at multiple sites in the $\mathrm{FVa}^{\mathrm{HC}}$, the generation of transient species with partial cofactor activity, and the ultimate disassociation of a fragment of the $\mathrm{FVa}^{\mathrm{HC}}$ from the molecule rendering it catalytically inactive. APC interacts with FVa or partially proteolyzed FVa species through their light chains to form enzyme-substrate complexes [23-25]. Additional studies have identified other regions of interaction, including the proteolytic target residues and the surrounding regions, in the FVa heavy chain involved in the enzyme substrate complex formation [26-28]. Three arginine residues are targeted in human $\mathrm{APC} \cdot \mathrm{FVa}$ complexes: $\mathrm{Arg}^{306}, \mathrm{Arg}^{506}$, and $\operatorname{Arg}^{679}[15,29]$. A number of studies have defined the activities of the partially proteolyzed FVa species [30,31]. Cleavage at either $\mathrm{Arg}^{306}$ or $\mathrm{Arg}^{506}$ results in cofactor species, $\mathrm{FVa}_{\mathrm{i}}^{306}$ and $\mathrm{FVa}_{\mathrm{i}}^{506}$, respectively, with reduced but similar cofactor activity in the prothrombinase complex (Figure 1) [30,31]. Cleavage at $\mathrm{Arg}^{306}$ has been shown to be essential for full loss of cofactor activity [32]. The significance of the cleavage at $\mathrm{Arg}^{679}$ remains undetermined. The final inactive cofactor, $\mathrm{FVa}_{\mathrm{i}}$, is a two chain molecule composed of the $\mathrm{FVa}^{\mathrm{LC}}$ and $\mathrm{FVa}^{1-306}$ fragment (Figure 1) [32]. The inactive cofactor binds APC with the same affinity as the intact cofactor [23,33], suggesting a potential role of product inhibition in regulating APC efficacy [33].

The complexity of this process led Hockin and coworkers to construct an ordinary differential equation based description of the network of reactions characterizing the process of bovine APC inactivation of bovine FVa using rate constants gleaned from studies with bovine, human and recombinant human proteins [33]. Empirical studies from a number of laboratories detailing APC inactivation of FVa have shown the cleavage at $\mathrm{Arg}^{506}$ preceding that at $\mathrm{Arg}^{306}$, with these data initially (often) being interpreted as indicating a sequential or ordered kinetic mechanism [15]. However, based on their mathematical modeling, Hockin et al. [33], concluded that the reaction pathway was better described as a random order cleavage process for $\mathrm{Arg}^{306}$ and $\mathrm{Arg}^{505}$ ( $\mathrm{Arg}^{506}$ in human FVa) in which each of the cleavages is independent of the other, but occurs at different rates (Figure 2), and where full loss of cofactor activity requires disassociation of the fragment of the $\mathrm{FVa}^{\mathrm{HC}}$ downstream from the $\mathrm{Arg}^{306}$ cleavage [32,33].

Numerous studies examining how components like FXa, prothrombin and protein S modulate APC inactivation of FVa have been reported [14,34-40]. These studies routinely employ approaches like progress curve analysis based on curve fitting to compare initial rates, or natural and recombinant cleavage site mutants to detail mechanistic features. To date, however, an integrated approach, one combining the use of physicochemical model construction based on prior research and model verification via construction of corresponding reaction systems using purified proteins, has not been extended to understand APC regulation of 


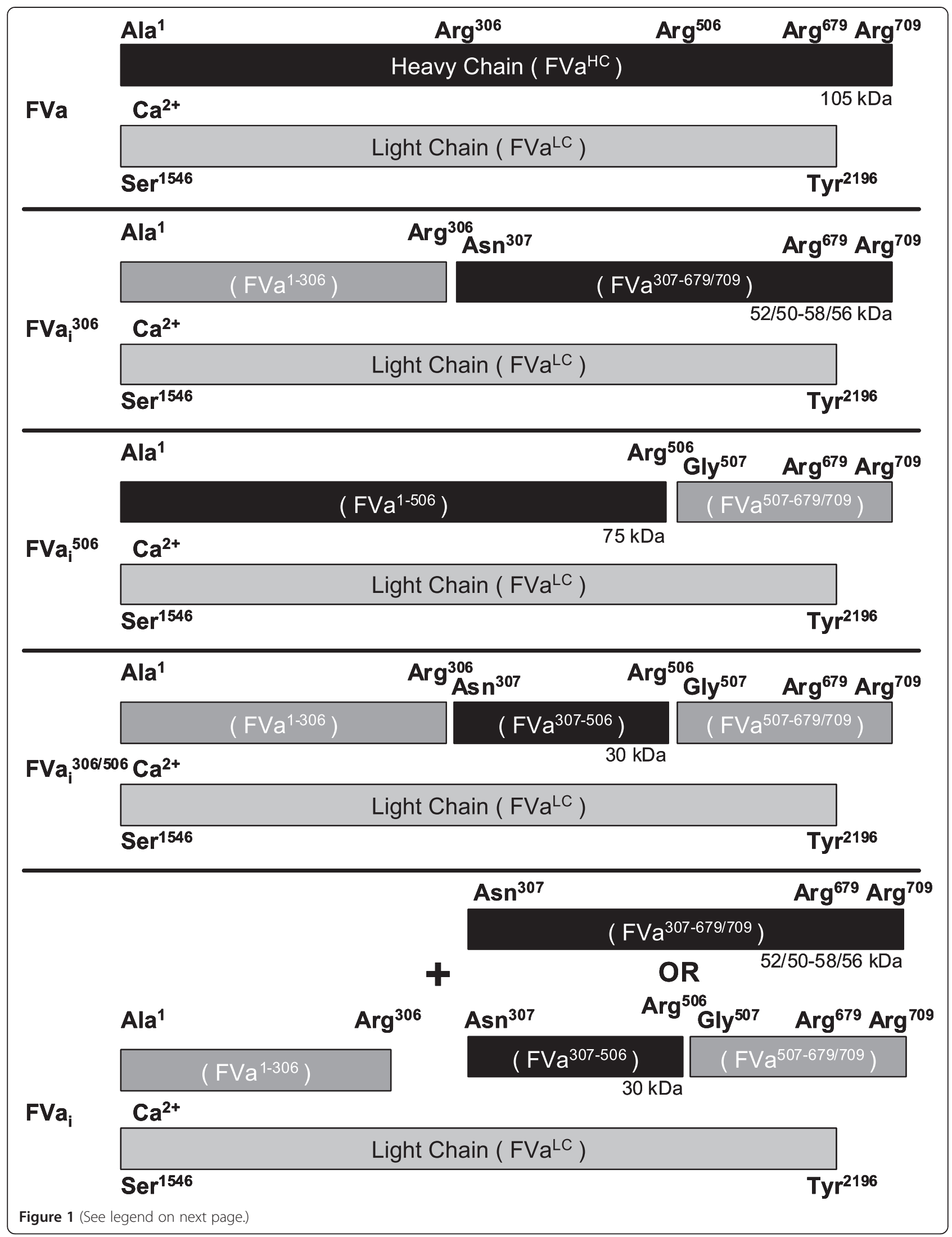


(See image on previous page.)

Figure 1 Schematic Representation of Factor Va and the Mechanism of the APC-Generated Partially Proteolyzed Species. Human factor $\mathrm{Va}$ (FVa), consisting of the non-covalently associated $105 \mathrm{kDa}$ heavy chain ( $\mathrm{FVa}^{\mathrm{HC}}$ ) and $74 / 72 \mathrm{kDa}$ light chain (two carbohydrate variants) ( $F a^{\mathrm{LC}}$ ),

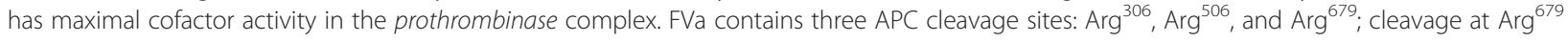
plays a minimal role in altering cofactor activity and so will not be considered further. APC cleaves FVa in a random, non-sequential manner at $\mathrm{Arg}^{306}$ and $\mathrm{Arg}^{506}$ leading to the formation of partially proteolyzed species ( $\mathrm{FVa}_{i}^{306}$ and $\mathrm{FVa}_{i}^{506}$, respectively). $\mathrm{FVa}_{i}^{306}$ and $\mathrm{FVa}_{i}^{506}$ are subsequently proteolyzed by APC at $\mathrm{Arg}^{506}$ or $\mathrm{Arg}^{306}$, respectively, to generate the $\mathrm{FVa}_{\mathrm{i}}^{306 / 506}$ species. Prothrombinase activity is possible even when the FVa ${ }^{\mathrm{HC}}$ has been proteolyzed at both sites as long as the heavy chain fragments remain associated with each other and the FVa ${ }^{\mathrm{LC}}$. The partially active $\mathrm{FVa}_{\mathrm{i}}^{306}$ and $\mathrm{FVa}_{\mathrm{i}}^{306 / 506}$ species lose full activity with the spontaneous dissociation of either the $\mathrm{FVa}^{307-679 / 709}$ or $\mathrm{FVa}^{307-506} \cdot \mathrm{FVa}^{507-679 / 709}$ fragments, respectively. Fragments shaded in black are recognized by the monoclonal antibody (aHFV\#17) and their apparent (SDS-PAGE) molecular weights are indicated.

the prothrombinase complex stability and function. In this study we build on the prior studies modeling APC inactivation of FVa [33] by incorporating the presence of additional components of the prothrombinase complex (FXa and prothrombin) to construct an empirically validated mathematical model. To test model constructs, a step-wise approach to increasing the number of components was used. Experiments were replicated multiple times with different preparations of proteins in order to generate robust data sets that included estimates of measurement error. At each level of complexity, we empirically monitored multiple analytes, including starting reactants, intermediates and final products to provide multiple points of comparison to evaluate each model's performance.

\section{Results and Discussion}

\section{APC Inactivation of Factor Va} Empirical Analyses

The inactivation of FVa $(20 \mathrm{nM})$ was monitored at two APC concentrations $(0.5$ and $2.0 \mathrm{nM})$ in the presence of excess PC:PS vesicles $(20 \mu \mathrm{M})$. The lower concentration of APC was used to initiate a slow inactivation reaction that would enable multiple time points to monitor the sequence of proteolytic events and the residual cofactor activity (as measured by a one stage clotting assay). In studies with $0.5 \mathrm{nM} \mathrm{APC}$, within one minute there was a $50 \%$ loss in cofactor activity (Figure 3, Panel A, black circles) which continued in a monophasic decay. According to previous studies, measurement of FVa cofactor activity as measured in clotting assays is sensitive to APC cleavage of $\mathrm{Arg}^{506}$ [41].

Western blot analyses (representative blot in Figure 3, Panel B) monitoring the disappearance of intact $\mathrm{FVa}^{\mathrm{HC}}$ (residues 1-709) display the rapid proteolysis of FVa heavy chain proteolyzed at either site within the first or third minutes with 2.0 or $0.5 \mathrm{nM}$ APC, respectively (Figure 3, Panel C, red and black circles, respectively). These results were each fit to monophasic exponential decays (fit not shown), and the initial slope of the fitted curve was determined after normalizing the densitometry to the maximal value (RMV). At $0.5 \mathrm{nM}$ APC, the initial rate of disappearance of the heavy chain was $200 \mathrm{pM} / \mathrm{s}$ (based on $20 \mathrm{nM}$ starting concentration); at $2.0 \mathrm{nM} \mathrm{APC}$, the rate of disappearance was nearly three-fold faster (558 $\mathrm{pM} / \mathrm{s})$. The disappearance of the heavy chain is initially concurrent with accumulation of the $\mathrm{FVa}^{1-506}$ fragment (Figure 3, Panel D). The generation of the $\mathrm{FVa}^{1-506}$ fragment reaches a maximum within $30 \mathrm{sec}(2.0 \mathrm{nM} \mathrm{APC})$ or $90 \mathrm{sec}(0.5$ nM APC) (Figure 3, Panel D, red and black circles, respectively). At this point most of the $\mathrm{FVa}^{\mathrm{HC}}$ has been proteolyzed primarily at $\mathrm{Arg}^{506}$, and the secondary cleavage at $\mathrm{Arg}^{306}$ in the $\mathrm{FVa}^{1-506}$ species becomes the dominant proteolytic event. Analysis of the appearance of the inactivation fragment $\mathrm{FVa}^{307-506}$ (resulting from cleavage at both $\mathrm{Arg}^{306}$ and $\mathrm{Arg}^{506}$, Figure 3, Panel E), indicates that as the $\mathrm{FVa}^{1-506}$ fragment is approaching its maximum level it is being further proteolyzed to

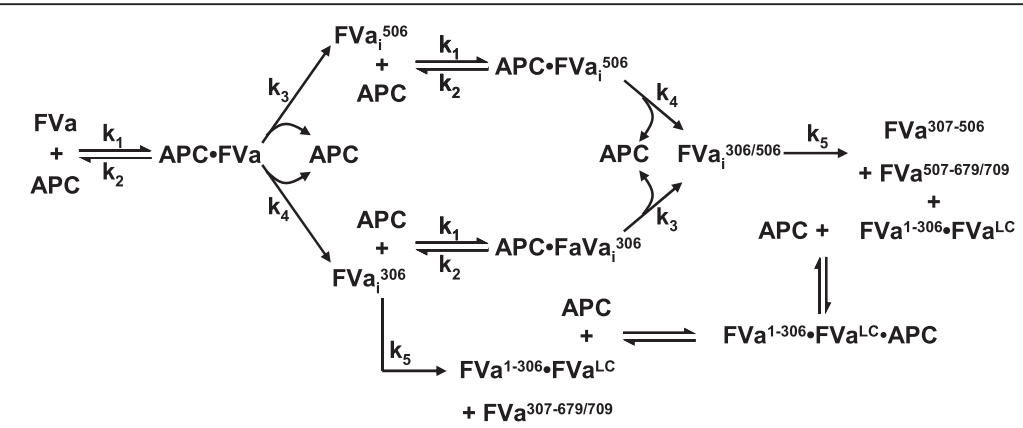

Figure 2 Mechanism of the APC Inactivation of Factor Va. Random non-ordered APC cleavage mechanism of bovine FVa proposed by Hockin et al. [33] renumbered with human FVa cleavages. 


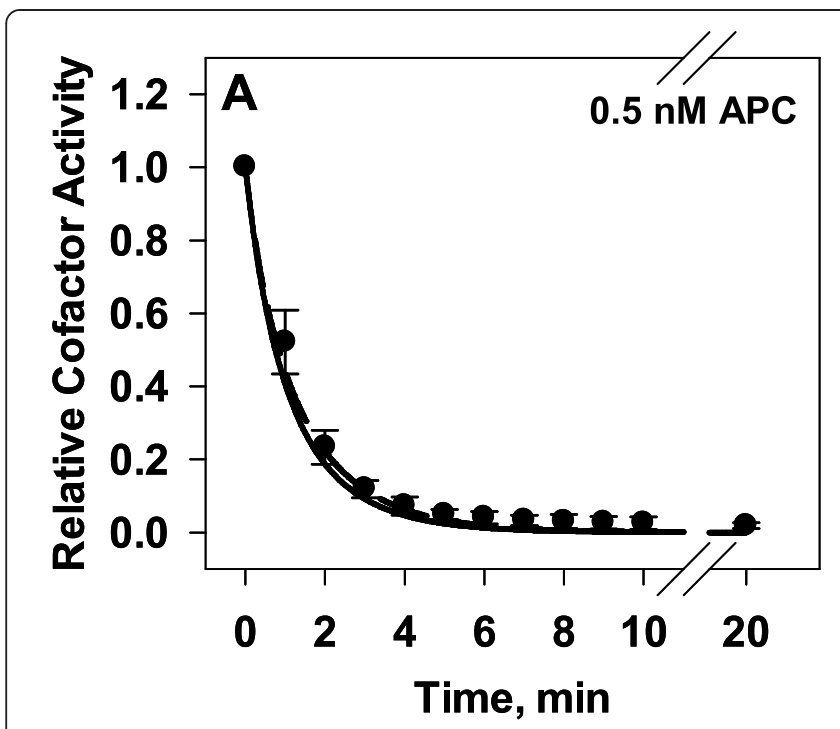

B
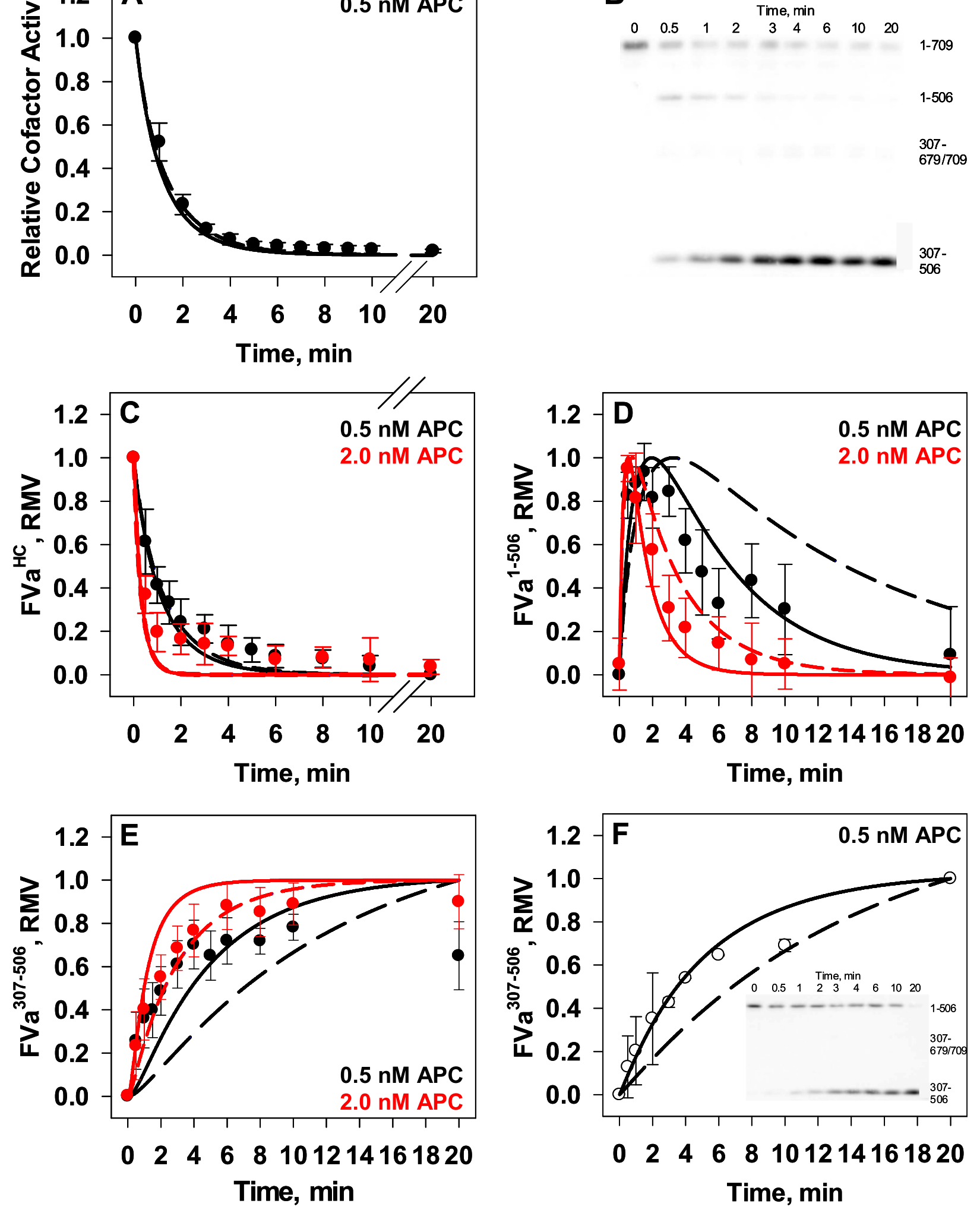

Figure 3 (See legend on next page.) 
(See image on previous page.)

Figure 3 Inactivation of Factor Va by Activated Protein C. Empirical: FVa (20 nM, Panels A-E) or FVa 506 (20 nM, Panel $F$ ) was incubated with PC:PS vesicles $(20 \mu \mathrm{M})$ and APC $(0.5$ or $2.0 \mathrm{nM})$ at $37^{\circ} \mathrm{C}$. All data points are presented as averages \pm S.D. of $4-6$ experiments for each time point. (A) Time course of APC ( $0.5 \mathrm{nM})$ inactivation of FVa. Cofactor activity is presented relative to activity present at zero point (black circles). (B) Representative Western blot of time course of APC (2.0 nM) inactivation of FVa. (C) Densitometric analyses of the disappearance of FVa ${ }^{H C}$ at 0.5 or $2.0 \mathrm{nM}$ APC (black and red circles, respectively). (D) Densitometric analyses of the time course of FVa ${ }^{1-506}$ at 0.5 or $2.0 \mathrm{nM}$ APC (black and red circles, respectively). (E) Densitometric analyses of the time course of $\mathrm{FVa}^{307-506}$ at 0.5 or $2.0 \mathrm{nM} \mathrm{APC}$ (black and red circles, respectively). ( $F$ ) Densitometric analyses of the inactivation fragment $\mathrm{FVa}^{307-506}$ generated during the APC (0.5nM) inactivation of FVa $\mathrm{a}_{i}^{506}$ (open circles). Inset displays a representative Western blot. Mathematical: Mathematically derived time courses of FVa inactivation by APC ( 0.5 nM - black lines and 2.0 $\mathrm{nM}$ - red lines) for the corresponding analytes are also presented in Panels A and C-F. Simulated time courses were generated using two sets of rate constants: Hockin et al. [33] - dashed lines; and current study - solid lines.

the $\mathrm{FVa}^{307-506}$ fragment. In order to isolate the kinetics of proteolysis at $\mathrm{Arg}^{306}, \mathrm{FVa}_{\mathrm{i}}^{506}$ was used as the starting material in inactivation studies with $0.5 \mathrm{nM} \mathrm{APC}$ (Figure 3, Panel F, open circles). This membrane bound partially proteolyzed species has already lost most of its cofactor activity in a clotting assay [30,31,33]. Tracking of the final inactivation fragment, $\mathrm{FVa}^{307-506}$, by Western blotting reveals a monophasic accumulation of this fragment (fit not shown) (Figure 3, Panel F).

\section{Mathematical Simulations}

Using the non-sequential reaction mechanism proposed by Hockin et al. (Table 1, Figure 2) [33] and kinetic constants used to describe their bovine system of proteins, in silico simulations of APC inactivation of FVa were performed and predicted time courses for various FVa inactivation species compared to the empirical data presented in Figure 3. Mathematical simulations show good correlation with empirical measurements of FVa cofactor activity and the densitometric analysis of $\mathrm{FVa}^{\mathrm{HC}}$ (Figure 3, Panel A and $\mathrm{C}$, dashed lines vs. filled circles, respectively). Hockin et al. reported a good fit using this model between simulated and empirical time courses of APC catalyzed changes in cofactor activity in the bovine system [33]. The present study's correlation between clotting assay measurements, in silico FVa cofactor activity, and densitometric analysis of $\mathrm{FVa}^{\mathrm{HC}}$ are consistent with the findings of earlier studies that FVa cofactor activity is based on the amount of intact $\mathrm{FVa}^{\mathrm{HC}}$ present [41].

However, the predicted generation and disappearance of the $\mathrm{FVa}^{1-506}$ fragment are significantly delayed compared to the empirical data for this inactivation fragment (Figure 3, Panel D, black dashed line vs. black circles). At $0.5 \mathrm{nM}$ APC, the simulation predicts that this fragment will reach a maximum at 3.4 min before slowly disappearing, with $30 \%$ still remaining after $20 \mathrm{~min}$; the empirical experiments show the peak level reached at 1.5 min with only $9 \%$ remaining after $20 \mathrm{~min}$ (Figure 3, Panel D, black dashed line vs. black circles). The mathematical simulation fared better with $2.0 \mathrm{nM}$ APC (Figure 3, Panel D, red dashed line vs. red circles) with respect to the timing of peak accumulation, however failed to recapitulate the rapid clearance of this fragment. Mathematical simulations of $\mathrm{FVa}^{307-506}$ using the Hockin et al. [33] rate constants resulted in an

Table 1 Equations describing APC inactivation of factor Va

\begin{tabular}{|c|c|c|c|c|c|}
\hline Eqn & Chemical Expression $^{a}$ & $\frac{k_{\text {off }}}{\left(s^{-1}\right)}$ & $\frac{k_{\text {on }}}{\left(M^{-1} s^{-1}\right)}$ & $\frac{k_{\text {cat }}}{\left(\mathrm{s}^{-1}\right)}$ & $\frac{k_{\text {dis }}}{\left(s^{-1}\right)}$ \\
\hline 1 & $\mathrm{APC}+\mathrm{FVa} \leftarrow 2-1 \rightarrow \mathrm{APC} \cdot \mathrm{FVa}$ & 0.7 & $1 \times 10^{8}$ & & \\
\hline 2 & $\mathrm{APC} \cdot \mathrm{FVa}-3 \rightarrow \mathrm{APC}+\mathrm{FVa}_{\mathrm{i}}^{506}$ & & & 1.0 & \\
\hline \multirow[t]{2}{*}{3} & $\mathrm{APC} \cdot \mathrm{FVa}-4 \rightarrow \mathrm{APC}+\mathrm{FVa}_{\mathrm{i}}^{306}$ & & & $0.064^{b}$ & \\
\hline & & & & $0.192^{c}$ & \\
\hline 4 & $\mathrm{APC}+\mathrm{FVa}_{\mathrm{i}}^{506} \leftarrow 2-1 \rightarrow \mathrm{APC} \cdot \mathrm{FVa}_{\mathrm{i}}^{506}$ & 0.7 & $1 \times 10^{8}$ & & \\
\hline 5 & $\mathrm{APC}+\mathrm{FVa}_{\mathrm{i}}^{306} \leftarrow 2-1 \rightarrow \mathrm{APC} \cdot \mathrm{FVa}_{\mathrm{i}}^{306}$ & 0.7 & $1 \times 10^{8}$ & & \\
\hline \multirow[t]{2}{*}{6} & $\mathrm{APC} \cdot \mathrm{FVa}_{\mathrm{i}}^{506}-4 \rightarrow \mathrm{APC}+\mathrm{FVa}_{\mathrm{i}}^{306 / 506}$ & & & $0.064^{b}$ & \\
\hline & & & & $0.192^{c}$ & \\
\hline 7 & $\mathrm{APC} \cdot \mathrm{FVa}_{\mathrm{i}}^{306}-3 \rightarrow \mathrm{APC}+\mathrm{FVa}_{\mathrm{i}}^{306 / 506}$ & & & 1.0 & \\
\hline 8 & $\mathrm{FVa}_{\mathrm{i}}^{306}-5 \rightarrow \mathrm{FVa}^{1-306} \cdot \mathrm{FVa}^{\mathrm{LC}}+\mathrm{FVa}^{307-679 / 709}$ & & & & 0.028 \\
\hline 9 & $\mathrm{FVa}_{\mathrm{i}}^{306 / 506}-5 \rightarrow \mathrm{FVa}^{1-306} \cdot \mathrm{FVa}^{\mathrm{LC}}+\mathrm{FVa}^{307-506}+\mathrm{FVa}^{507-679 / 709}$ & & & & 0.028 \\
\hline 10 & $\mathrm{APC}+\mathrm{FVa}^{1-306} \cdot \mathrm{FVa}^{\mathrm{LC}} \leftarrow 2-1 \rightarrow \mathrm{APC} \cdot \mathrm{FVa}^{1-306} \cdot \mathrm{FVa}^{\mathrm{LC}}$ & 0.7 & $1 \times 10^{8}$ & & \\
\hline
\end{tabular}

${ }^{a}$ For equilibrium expressions denoted by $\leftarrow 2-1 \rightarrow$, the first number listed describes the reverse reaction given in the $\mathrm{k}_{\text {off }}$ column.

${ }^{b}$ Rate constant used for mathematical simulations as determined by inactivation studies with bovine FVa and bovine APC in Hockin et al. [33].

c Rate constant used for mathematical simulations, as determined by inactivation studies with human FVa and human APC in this study, is $0.192 \mathrm{~s}^{-1}$. This new rate constant will be used in all subsequent mathematical simulations. 
estimated six-fold slower accumulation of this fragment compared to empirical data (Figure 3, Panel E, dashed lines vs. circles).

Though the bovine based Hockin et al. [33] rate constants clearly captured the disappearance of $\mathrm{FVa}^{\mathrm{HC}}$ as measured through activity and fragment analysis, they did not accurately predict the presentation of either the $\mathrm{FVa}^{1-506}$ or $\mathrm{FVa}^{307-506}$ fragments in the human system. The rapid clearance of the $\mathrm{FVa}^{1-506}$ fragment and faster appearance of the smaller $\mathrm{FVa}^{307-506}$ fragment led us to speculate that their model rate constant for the cleavage at $\mathrm{Arg}^{306}$ was not appropriate for the human system of proteins. From a comparison of the empirical data to the initial in silico simulation we estimated that the rate of cleavage occurring at $\mathrm{Arg}^{306}$ was three times faster than the model predictions. To account for this the rate constant (Figure 2, $\mathrm{k}_{4}$; Table 1, Eqns 3 and 6) in the mathematical model was adjusted from $0.064 \mathrm{~s}^{-1}$ to $0.192 \mathrm{~s}^{-1}$ and simulations rerun for all analytes (Figure 3, solid lines). As expected the simulated predictions for $\mathrm{FVa}$ cofactor activity and $\mathrm{FVa}^{\mathrm{HC}}$ were minimally altered by this change and continued to correlate well with their respective empirical measures (Figure 3, Panels A and C, solid lines vs. filled circles). The adjusted rate constant significantly altered the in silico predictions for both smaller FVa inactivation fragments (Figure 3, Panels D and E, solid lines vs. dashed lines) yielding a better fit with empirical results. The revised model using the adjusted kinetic rate was extended to experiments conducted with $\mathrm{FVa}_{\mathrm{i}}^{506}$ and the predicted time courses for the two models compared to the empirical results (Figure 3, Panel F, solid lines and dashed lines vs. open circles). As can be seen in all simulations, those using the published bovine model values (Figure 3, dashed lines) resulted in a poorer fit [33]. The rate constant for cleavage at $\mathrm{Arg}^{306}, \mathrm{k}_{4}$, was adjusted to $0.192 \mathrm{~s}^{-1}$ for all subsequent studies.

Our empirically driven adjustment to $\mathrm{k}_{4}$ results in a second order rate constant for the overall process of cleavage at $\mathrm{Arg}^{306}$ of $2.74 \times 10^{7} \mathrm{M}^{-1} \mathrm{~s}^{-1}$. Previously published second order rate constants for the APC cleavage at $\mathrm{Arg}^{306}$ in human FVa $\left(1.55 \times 10^{6} \mathrm{M}^{-1} \mathrm{~s}^{-1}\right.$ [42], $1.7 \times 10^{6} \mathrm{M}^{-1} \mathrm{~s}^{-1}$ [31], and $2.5 \times 10^{6} \mathrm{M}^{-1} \mathrm{~s}^{-1}$ [41]) are an order of magnitude lower than our currently derived estimate and lower than that used by Hockin et al. $\left(9.1 \times 10^{6} \mathrm{M}^{-1} \mathrm{~s}^{-1}\right.$ [33]) to describe the bovine system.

Studies using human proteins on APC inactivation of FVa reported second order rate constants for the cleavage at $\mathrm{Arg}^{506}$ ranging from 3.0-4.3 $\times 10^{7} \mathrm{M}^{-1} \mathrm{~s}^{-1}[31,41]$; a more recent study by Nicolaes et al. [42] has reported the second order rate constant to be $1.17 \times 10^{8} \mathrm{M}^{-1} \mathrm{~s}^{-1}$. This value is quite similar to the value $\left(1.42 \times 10^{8} \mathrm{M}^{-1} \mathrm{~s}^{-1}\right)$ used in the current study.

An alternative approach to fitting these data sets would have been to use an optimization method in which all rate constants may be simultaneously adjusted to generate a best fit to all the experimental data. Failure of model predictions to fit the empirical data can stem from the collective effect of small errors in the rate constants used. It is not uncommon for laboratories to report 2-3 fold differences in rate constants of biochemical reactions and interactions measured in vitro. These ranges are accepted because the findings would fall within the margin of error expected for slightly variable experiments conducted in different laboratories, or for different techniques used to measure a rate constant. Such variation can have significant effects on model outputs [43]. However, lack of fit can arise from a fundamental mistake or omitted interaction in the reaction description. Therefore, we have not taken this approach as we developed this model.

\section{APC Inactivation of Factor Va: Effect of Factor Xa Under Non-saturating Conditions}

It has been widely reported that FXa shields FVa from degradation by APC through its reversible association in the prothrombinase (FXa·FVa) complex [34-38,44]. The mechanistic basis of this protection has been conceptualized as a mutually exclusive competition for association with membrane bound FVa, so that when FVa is associated with FXa it is not a substrate for APC [35], at least at the Arg ${ }^{506}$ site [37]. In order to develop a model description that can predict the extent of the protective effect exerted by FXa against APC proteolysis of FVa over a range of reactant concentrations, empirical experiments were performed at saturating and non-saturating concentrations of FXa.

\section{Empirical Analyses}

In the first set of experiments, prothrombinase was preformed under non-saturating concentrations with FVa in excess (0.2 nM FVa and $0.1 \mathrm{nM} F X a)$ on $20 \mu \mathrm{M}$ PC:PS vesicles. Under these conditions, if the $K_{D}=0.5 \mathrm{nM}$ for the $(\mathrm{FXa} \cdot \mathrm{FVa})$ complex (estimate based on previous studies [45]), only $13 \%$ of the FVa would be expected to be bound to FXa. Inactivation reactions were initiated with 0 , 0.5, or $2.0 \mathrm{nM}$ APC. For these experiments, the amount of thrombin generated in the $0 \mathrm{nM}$ APC control was set at $100 \%$ prothrombinase activity, with thrombin generation levels represented relative to the prothrombinase activity in the $0 \mathrm{nM}$ APC control. The loss of prothrombinase activity following the addition of APC at either concentration (Figure 4, Panel A, filled circles) appeared to follow a monophasic decay (fits not shown).

\section{Mathematical Simulations}

To simulate this experiment, six additional equations were required (Table 2, Eqns 11-16). Of these, four equations describe the formation of a prothrombinase complex between FXa and FVa (FXa•FVa) or any of the three partially proteolyzed $\mathrm{FVa}$ species $\left(\mathrm{FXa} \cdot \mathrm{FVa}_{\mathrm{i}}^{506}\right.$, 


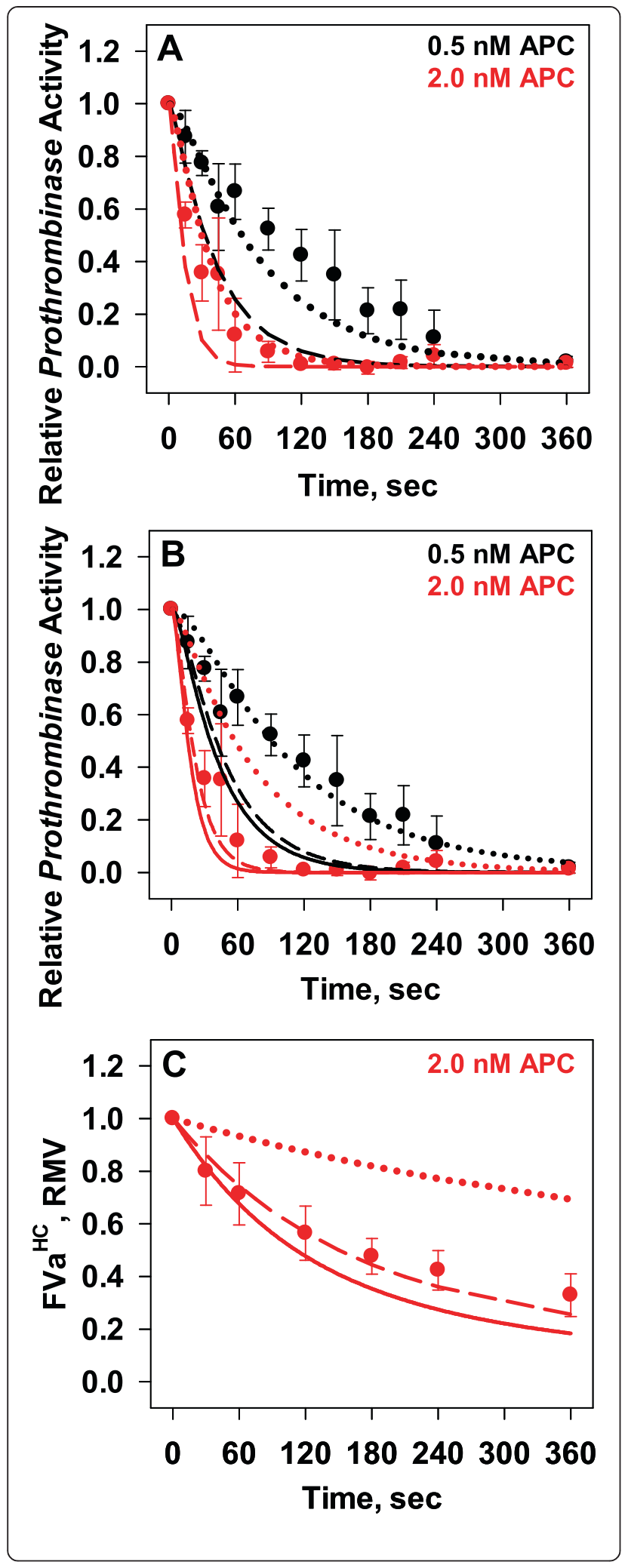

Figure 4 Effect of Factor Xa on Activated Protein C Inactivation of Factor Va. Empircal time courses of FVa inactivation measured by activity analysis (Panels $A$ and $B$ ) or by monitoring proteolytic cleavages (Panel $C$ ) are presented along with corresponding simulated time courses. All data points are presented as averages \pm S.D. of $4-6$ experiments. $(A, B)$ Empirical time courses of APC (0.5 nM - black circles; $2.0 \mathrm{nM}$ - red circles) inactivation of preformed prothrombinase (200 pM FVa and 100 pM FXa). Corresponding simulated time courses for $0.5 \mathrm{nM}$ (black) or $2.0 \mathrm{nM}$ (red) APC are presented with three potential $K_{D}$ values for the formation of the prothrombinase complex (100 pM - dotted lines; $500 \mathrm{pM}$ - dashed lines; $750 \mathrm{pM}$ - solid line): in Panel $A$ each equilibrium process was described using a $\mathrm{k}_{\mathrm{on}}\left(4.0 \times 10^{8} \mathrm{M}^{-1} \mathrm{~s}^{-1}\right)$ and adjusting the $\mathrm{k}_{\text {off }}$ constant; in Panel $B$ each equilibrium process was described using a $k_{\text {on }}\left(1.5 \times 10^{8} \mathrm{M}^{-1} \mathrm{~s}^{-1}\right)$ and adjusting the $\mathrm{k}_{\text {off }}$ constant. (C) Empirical time course of $2.0 \mathrm{nM}$ APC inactivation of preformed prothrombinase (20 nM FVa and $30 \mathrm{nM}$ FXa*) anaylzed by Western blotting. $\mathrm{FV}^{\mathrm{HC}}$ densitometric data are expressed as relative to its value at time 0 (red circles). Corresponding simulated time courses for $2.0 \mathrm{nM}$ (red) APC are presented using three potential $K_{D}$ values for the formation of the prothrombinase complex with each equilibrium process described by using a $\mathrm{k}_{\text {on }}\left(1.5 \times 10^{8} \mathrm{M}^{-1} \mathrm{~s}^{-1}\right)$ and adjusting the $\mathrm{k}_{\text {off }}$ constant (100 pM - dotted lines; $500 \mathrm{pM}$ - dashed lines; 750 pM - solid line).

$\mathrm{FXa} \cdot \mathrm{FVa}_{\mathrm{i}}^{306}$, and $\mathrm{FXa} \cdot \mathrm{FVa}_{\mathrm{i}}^{306 / 506}$ ) using a $\mathrm{K}_{\mathrm{D}}$ twice that describing the complex formed with intact FVa (FXa・FVa) (based on previous studies [32]). Several empirical studies using plasma derived FVa and recombinant FVa mutants have demonstrated that $\mathrm{FVa}_{\mathrm{i}}^{506}$ and $\mathrm{FVa}_{\mathrm{i}}^{306}$ can complex with FXa and form a productive enzyme complex $[31,32,41]$. Two additional equations allow for the dissociation of heavy chain fragments from the prothrombinase species formed with either $\mathrm{FVa}_{\mathrm{i}}^{306}$ or $\mathrm{FVa}_{\mathrm{i}}^{306 / 506}$.

Our initial mathematical simulations were carried out utilizing a $\mathrm{K}_{\mathrm{D}}$ of $0.5 \mathrm{nM}$ [45], resulting in an initial concentration of $26 \mathrm{pM}$ for prothrombinase, with off and on rates of $0.2 \mathrm{~s}^{-1}$ and $4.0 \times 10^{8} \mathrm{M}^{-1} \mathrm{~s}^{-1}$, respectively (Table 2, Eqn 11) [46,47]. The mathematical predictions for the loss of prothrombinase activity in the presence of either 0.5 or $2.0 \mathrm{nM}$ APC showed an approximately 2 -fold faster loss in prothrombinase activity than observed in the empirical experiments (Figure 4, Panel A, dashed lines vs. filled circles).

To generate a better fit to the empirical data we first examined the dissociation constant of FXa and FVa on PC:PS vesicles, which by literature reports varies from as low as $83 \mathrm{pM}$ [31] to as high as $1 \mathrm{nM}$ [48]. Simulations to test the wide range of reported $K_{D}$ values were first conducted by altering the $\mathrm{k}_{\text {off }}$ rate constants for the prothrombinase complex, while maintaining the same $\mathrm{k}_{\text {on }}$ rate constant of $4.0 \times 10^{8} \mathrm{M}^{-1} \mathrm{~s}^{-1}$. For each $\mathrm{K}_{\mathrm{D}}$ value tested, the starting concentrations of free and bound species (FVa, FXa, and FXa.FVa) were recalculated and used as the initial conditions for a mathematical simulation. An adjustment made to the off rate for the prothrombinase complex resulting in a $\mathrm{K}_{\mathrm{D}}$ of $0.1 \mathrm{nM}(58.8$ 
Table 2 Equations describing interactions between intact and partially proteolyzed factor Va with factor Xa and prothrombin

\begin{tabular}{|c|c|c|c|c|}
\hline \multirow[t]{2}{*}{ Eqn } & \multirow[t]{2}{*}{ Chemical Expression } & \multirow{2}{*}{$\frac{k_{\text {off }}}{\left(s^{-1}\right)}$} & \multirow{2}{*}{$\frac{k_{\text {on }}}{\left(M^{-1} s^{-1}\right)}$} & \multirow{2}{*}{$\frac{k_{\text {dis }}}{\left(s^{-1}\right)}$} \\
\hline & & & & \\
\hline \multirow[t]{2}{*}{11} & $\mathrm{FXa}+\mathrm{FVa} \leftarrow 7-6 \rightarrow \mathrm{FXa} F \mathrm{FVa}$ & $0.2^{a} 0.075^{b}$ & $4 \times 10^{8} \mathrm{a}$ & \\
\hline & & & $1.5 \times 10^{8} \mathrm{~b}$ & \\
\hline \multirow[t]{2}{*}{12} & $\mathrm{FXa}+\mathrm{FVa}_{\mathrm{i}}^{506} \leftarrow 8-6 \rightarrow \mathrm{FXa}^{5} \cdot \mathrm{FVa}_{\mathrm{i}}^{506}$ & $0.4^{c}$ & $4 \times 10^{8 c}$ & \\
\hline & & $0.15^{b}$ & $1.5 \times 10^{8 \mathrm{~b}}$ & \\
\hline \multirow[t]{2}{*}{13} & $\mathrm{FXa}+\mathrm{FVa}_{\mathrm{i}}^{306} \leftarrow 8-6 \rightarrow \mathrm{FXa}^{3} \cdot \mathrm{FVa}_{\mathrm{i}}^{306}$ & $0.4^{\mathrm{c}}$ & $4 \times 10^{8 c}$ & \\
\hline & & $0.15^{b}$ & $1.5 \times 10^{8} \mathrm{~b}$ & \\
\hline \multirow[t]{2}{*}{14} & $\mathrm{FXa}+\mathrm{FVa}_{\mathrm{i}}^{306 / 506} \leftarrow 8-6 \rightarrow \mathrm{FXa}^{2} \cdot \mathrm{FVa}_{\mathrm{i}}^{306 / 506}$ & $0.4^{c}$ & $4 \times 10^{8 c}$ & \\
\hline & & $0.15^{b}$ & $1.5 \times 10^{8} \mathrm{~b}$ & \\
\hline 15 & $\mathrm{FXa} \cdot \mathrm{FVa}^{306}-9 \rightarrow \mathrm{FXa}+\mathrm{FVa}^{1-306} \cdot \mathrm{FVa}^{\mathrm{LC}}+\mathrm{FVa}^{307-679 / 709}$ & & & 0.0035 \\
\hline 16 & $\mathrm{FXa} \cdot \mathrm{FVa}_{\mathrm{i}}^{306 / 506}-9 \rightarrow \mathrm{FXa}+\mathrm{FVa}^{1-306} \cdot \mathrm{FVa}^{\mathrm{LC}}+\mathrm{FVa}^{307-506}+\mathrm{FVa}^{507-679 / 709}$ & & & 0.0035 \\
\hline 17 & $\mathrm{FVa}+\mathrm{PT} \leftarrow 11-10 \rightarrow \mathrm{FVa} \cdot \mathrm{PT}$ & $70^{d}$ & $1 \times 10^{8}$ & \\
\hline
\end{tabular}

pM prothrombinase initially) generated an in silico prediction that more closely represented the empirical results seen with both 0.5 and $2.0 \mathrm{nM}$ APC (Figure 4, Panel A, black and red, respectively, dotted lines vs filled circles).

In addition to altering the $\mathrm{k}_{\text {off }}$ rate constant while maintaining $a k_{\text {on }}$ rate constant to reach a desired overall $K_{\mathrm{D}}$, changes to both isolated rate constants were explored as a potential solution. One alternative that we explored was adjusting the $\mathrm{k}_{\text {on }}$ rate constant to $1.5 \times 10^{8} \mathrm{M}^{-1} \mathrm{~s}^{-1}$ and setting the $\mathrm{k}_{\text {off }}$ rate constant to values that yielded the same set of $K_{D}$ values. Figure 4, Panel B presents these model results at 0.5 and $2.0 \mathrm{nM}$ APC (black and red, respectively) for $\mathrm{K}_{\mathrm{D}}$ 's of $0.5 \mathrm{nM}$ (dashed lines) and $0.1 \mathrm{nM}$ (dotted lines) for prothrombinase assembly. In contrast to simulations based with a $\mathrm{k}_{\text {on }}$ value of $4.0 \times 10^{8} \mathrm{M}^{-1} \mathrm{~s}^{-1}$ this analysis indicates that a $K_{D}$ of $0.5 \mathrm{nM}$ yields a better fit to the data.

These results highlight an important feature of dynamic systems like this one: the magnitude of the observed protective effect may depend not only on the concentrations of the three protein components and the $K_{D}$ 's characterizing their interactions, but also on the rate constants defining the competing $\mathrm{K}_{\mathrm{D}}$ 's.

\section{APC Inactivation of Factor Va: Effect of Factor Xa Under Saturating Conditions}

The previous analysis under non-saturating conditions indicates that either a dissociation constant of $0.1 \mathrm{nM}$ or $0.5 \mathrm{nM}$ for the prothrombinase complex can recapitulate our empirical data depending on the values assigned to

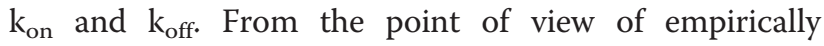

measuring $\mathrm{k}_{\mathrm{on}}$ and $\mathrm{k}_{\mathrm{off}}$ values the differences in these assigned values (e.g. $\sim 2.5$ fold between 1.5 or $4.0 \mathrm{x}$ $10^{8} \mathrm{M}^{-1} \mathrm{~s}^{-1}$ ) are small and within the margin of error for this type of analysis. In order to further explore which dissociation constant and set of rate constants is appropriate for the empirical data, we tested APC inactivation of FVa under saturating conditions with FXa present in excess (Figure 4, Panel $\mathrm{C}$ and Figure 5).

\section{Empirical Analyses}

Figure 5 presents empirical experiments in which preformed prothrombinase (20 nM FVa and $30 \mathrm{nM}$ active site blocked FXa $\left.\left(\mathrm{FXa}^{*}\right)\right)$ was treated with $2.0 \mathrm{nM}$ APC and time courses of $\mathrm{FVa}^{\mathrm{HC}}$ and its APC-derived fragments $\mathrm{FVa}^{1-506}, \mathrm{FVa}^{307-679 / 709}$ and $\mathrm{FVa}^{307-506}$ visualized by Western blotting (Figure 5, Panel A, inset). Under these conditions, $95 \%$ to $99 \%$ of the FVa is bound to $\mathrm{FXa}^{*}$ prior to addition of APC given $\mathrm{K}_{\mathrm{D}}$ values in the range of $0.5 \mathrm{nM}$ to $0.1 \mathrm{nM}$, respectively. The selection of $20 \mathrm{nM}$ FVa reflected the fact that in closed model systems of TF-initiated coagulation, levels of FVa reach $20 \mathrm{nM}$ [49] and the practical requirement for a concentration suitable for Western blot analysis. Active site blocked FXa was used to prevent FXa proteolysis of FVa [50].

Reactions where the FVa population is highly associated with $\mathrm{FXa}^{*}$ showed $70 \%$ of $\mathrm{FVa}^{\mathrm{HC}}$ remained after 1 minute (Figure 4, Panel C and Figure 5, Panel A, red circles) compared to $\sim 10 \%$ without $\mathrm{FXa}^{*}$ (Figure 3, Panel $\mathrm{C}$, red circles). Comparison of initial rates showed a greater than 7 -fold reduction in the initial rate of $2.0 \mathrm{nM}$ APC proteolysis of FVa due to its FXa association ( $77 \mathrm{pM} / \mathrm{s}$ vs. 558 $\mathrm{pM} / \mathrm{s}$ ). Consistent with this overall suppression of heavy 


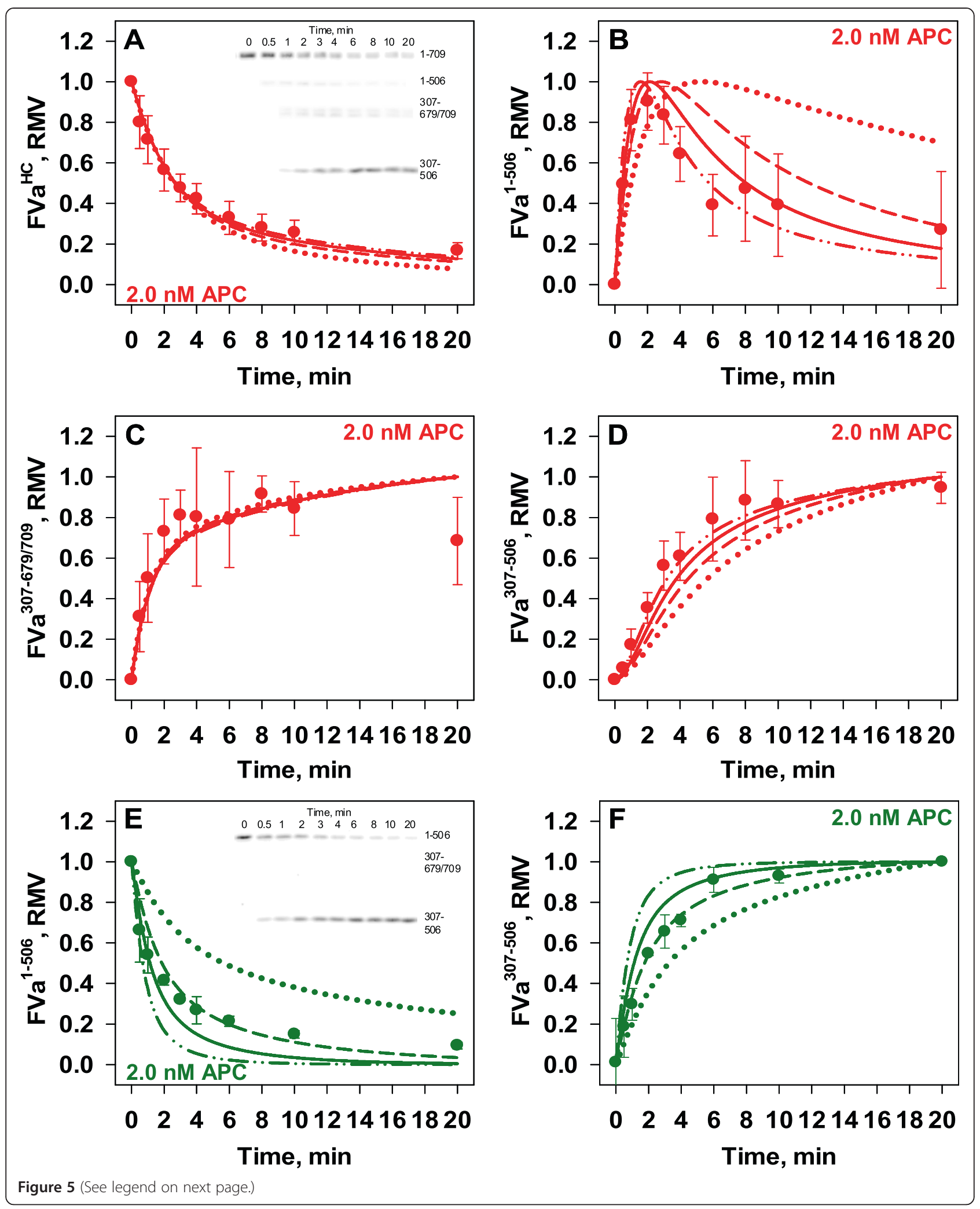


(See figure on previous page.)

Figure 5 APC Inactivation of FVa in the Presence of a Saturating Concentration of FXa. Empirical: FVa (20 nM, Panels A-D) or FVa $a_{i}^{506}(20$ nM, Panel $E$ and $F$ ) was pre-incubated with active site blocked $F X^{*}(30 \mathrm{nM})$ at $37^{\circ} \mathrm{C}$. The reaction was then initiated with $2.0 \mathrm{nM}$ APC. The inactivation of FVa was monitored by densitometry for the following fragments: $\mathrm{FVa}^{\mathrm{HC}}$ (Panel A), FVa ${ }^{1-506}(B), \mathrm{FVa}^{307-679 / 709}(C)$ and $\mathrm{FVa}^{307-506}(D)$ and the inactivation of $\mathrm{FVa}_{i}^{506}$ was monitored by following $\mathrm{FVa}^{1-506}(E)$ and $\mathrm{FVa}^{307-506}(\mathrm{~F})$. All data points with FVa are presented as averages \pm S.D. of 4-6 experiments and data points with $\mathrm{FVa}_{\mathrm{i}}^{506}$ are presented as averages \pm S.D. of 2 experiments. Mathematical: Simulated time courses in which the model description does not allow APC proteolysis of the FXa*FVai $a_{i}^{506}$ complex (dotted line) or allows the cleavage by APC at Arg ${ }^{306}$ in the FXa*FVai ${ }_{i}^{506}$ complex with rate constants of $2.5 \times 10^{6} \mathrm{M}^{-1} \mathrm{~s}^{-1}$ (dashed line), $5.0 \times 10^{6} \mathrm{M}^{-1} \mathrm{~s}^{-1}$ (solid line), or $9.1 \times 10^{6} \mathrm{M}^{-1} \mathrm{~s}^{-1}$ (dash with dotted line).

chain proteolysis, generation of the $\mathrm{FVa}^{1-506}$ fragment was slower in the presence of FXa*, reaching a maximum in $2 \mathrm{~min}$ vs $\sim 30 \mathrm{~s}$ in its absence (Figure 5, Panel B vs. Figure 3, Panel D, red circles). Its clearance was also suppressed, taking $\sim 4 \mathrm{~min}$ to decline to $50 \%$ of its maximum as opposed to $\sim 1$ min without FXa* (Figure 5, Panel B vs. Figure 3, Panel D, red circles).

In contrast to APC inactivation studies conducted in the absence of $\mathrm{FXa}^{*}$, visual inspection of Western blot images (Figure 5, Panel A, inset) reveal the accumulation of the $\mathrm{FVa}^{307-679 / 709}$ fragment leading to more reliable quantitative densitometric analysis of this fragment (Figure 5, Panel C, red circles). Generation of this fragment reaches $50 \%$ of its maximal level by 1 minute, and remains at elevated levels above $70 \%$ of maximal level after 2 minutes (Figure 5, Panel C, red circles). Generation of the $\mathrm{FVa}^{307-506}$ fragment reaches $50 \%$ of maximal value after 3 minutes (Figure 5, Panel D, red circles).

\section{Mathematical Simulations}

Initial prothrombinase concentrations given the condition of pre-incubating $20 \mathrm{nM}$ FVa and $30 \mathrm{nM} \mathrm{FXa*}$ were calculated to be $19.1 \mathrm{nM}$ or $19.8 \mathrm{nM}$ using $K_{\mathrm{D}}$ values of either $0.5 \mathrm{nM}$ or $0.1 \mathrm{nM}$, respectively. A range of $\mathrm{k}_{\mathrm{on}}$ and $k_{\text {off }}$ rate constants for each $K_{D}$ were tested by varying $\mathrm{k}_{\text {on }}$ values between 1 and $4.0 \times 10^{8} \mathrm{M}^{-1} \mathrm{~s}^{-1}$. Time courses of the inactivation of FVa by $2.0 \mathrm{nM}$ APC were produced. The results of this in silico study indicated that the disappearance of $\mathrm{FVa}^{\mathrm{HC}}$ was dependent on the resultant $K_{D}$ value and independent of the combination of $k_{\text {on }}$ and $k_{\text {off }}$ rate constants used to generate the $K_{D}$ values of 0.1 or $0.5 \mathrm{nM}$ (data not shown). Assuming the $K_{\mathrm{D}}$ for prothrombinase is $0.1 \mathrm{nM}$ and the $\mathrm{k}_{\mathrm{on}}$ is either $1.5 \times 10^{8} \mathrm{M}^{-1} \mathrm{~s}^{-1}$ or $4.0 \times 10^{8} \mathrm{M}^{-1} \mathrm{~s}^{-1}$, the model predicts that after $6 \mathrm{~min} 25 \%$ of the $\mathrm{FVa}^{\mathrm{HC}}$ is proteolyzed (Figure 4, Panel C, red dotted line), in contrast to the empirical results showing $\sim 82 \%$ of $\mathrm{FVa}^{\mathrm{HC}}$ proteolyzed at 6 minutes (Figure 4, Panel $\mathrm{C}$, red circles). Model simulations with $\mathrm{K}_{\mathrm{D}}$ values of $0.5 \mathrm{nM}, 0.75 \mathrm{nM}$ or 1.0 $\mathrm{nM}$ resulted in $\mathrm{FVa}^{\mathrm{HC}}$ levels decreasing after 6 min by $75 \%$ (Figure 4, Panel C, red dashed line), $83 \%$ (Figure 4, Panel C, red solid line), or $87 \%$ (data not shown), respectively. From the mathematical simulations, the initial rates of $\mathrm{FVa}^{\mathrm{HC}}$ proteolysis were $22 \mathrm{pM} / \mathrm{s}, 86 \mathrm{pM} / \mathrm{s}$, and $122 \mathrm{pM} / \mathrm{s}$ for $\mathrm{K}_{\mathrm{D}}$ 's of $0.1 \mathrm{nM}, 0.5 \mathrm{nM}$, and $0.75 \mathrm{nM}$, respectively, compared to the empirically derived rate of $\mathrm{FVa}^{\mathrm{HC}}$ proteolysis of $78 \mathrm{pM} / \mathrm{s}$. Overall these comparisons support our eliminating $0.1 \mathrm{nM}$ as the $\mathrm{K}_{\mathrm{D}}$ for the prothrombinase complex.

While the mathematical model is able to recapitulate the overall combined initial cleavages of $\mathrm{FVa}^{\mathrm{HC}}$ (Figure 5, Panel A, dotted line vs. filled circles), there is a mixed success for the predictions of the inactivation fragments (Figure 5, Panels B-D, dotted line vs. filled circles). Specifically, the mathematical model captures the rapid accumulation of the FVa ${ }^{307-679 / 709}$ fragment (Figure 5, Panel C, dotted line), but does not capture the clearance of the $\mathrm{FVa}^{1-506}$ fragment (Figure 5, Panel B, dotted line) or the generation of the $\mathrm{FVa}^{307-506}$ fragment (Figure 5, Panel D). The same lack of fit for the proteolysis of this fragment is observed when $\mathrm{FVa}_{\mathrm{i}}^{506}$ is the starting substrate (Figure 5, Panels E and F, dotted line vs. filled circles).

In the mathematical model as constructed APC proteolysis at any site is permitted only with FVa species not bound to FXa (or $\mathrm{FXa}^{*}$ ). The more rapid clearance of $\mathrm{FVa}^{1-506}$ observed empirically suggests two possible problems with the model construct: 1) the binding affinity between $\mathrm{FVa}_{\mathrm{i}}^{506}$ and $\mathrm{FXa}$ is weaker than the model value of $1 \mathrm{nM}$ based on studies with bovine FVa [32] or 2) APC can cleave at $\mathrm{Arg}^{306}$ when the $\mathrm{FVa}_{\mathrm{i}}^{506}$ species is bound to FXa. Previous studies with recombinant human proteins have reported $K_{D}$ values ranging from $\sim 3.9 \mathrm{nM}$ [31] to $1.35 \mathrm{nM}$ [51]. To evaluate the likelihood that a weaker binding affinity was the culprit, mathematical simulations were conducted where the $K_{D}$ for the $\mathrm{FXa} \cdot \mathrm{FVa}_{\mathrm{i}}^{506}$ complex was varied; to fit the empirical data the $K_{D}$ for this complex would have to be greater than $10 \mathrm{nM}$ (data not shown) and as such this adjustment was discarded as a viable option.

The alternative explanation for the empirical data presenting the clearance of the $\mathrm{FVa}^{1-506}$ fragment is that when bound to $\mathrm{FXa}$, the $\mathrm{FVa}_{\mathrm{i}}^{506}$ species is susceptible to APC cleavage at $\mathrm{Arg}^{306}$. To explore this hypothesis, an additional reaction was added to the mathematical construct: APC cleaving $\left(\mathrm{FXa} \cdot \mathrm{FVa}_{\mathrm{i}}^{506}\right)$ at $\mathrm{Arg}^{306}$. To establish whether there was a value for this rate constant that would improve the fit, simulations varying its value were run using the model value $\left(2.7 \times 10^{7} \mathrm{M}^{-1} \mathrm{~s}^{-1}\right)$ for the cleavage of $\mathrm{Arg}^{306}$ in free FVa as a point of reference. Representative examples are presented in Figure 5. The mathematical analysis suggests 
that if the $\mathrm{Arg}^{306}$ in $\left(\mathrm{FXa}^{\circ} \mathrm{FVa}_{\mathrm{i}}^{506}\right)$ is a target for APC, the magnitude of the rate constant regulating the event is $\sim 10$ to $20 \%$ that for free FVa.

\section{Structural Analysis}

Analysis of the proposed structural models of the prothrombinase complex allows for the possibility that $\mathrm{Arg}^{306}$ is susceptible to APC in the $\mathrm{FXa}^{3} \mathrm{FVa}_{\mathrm{i}}^{506}$ complex [52-54]. The prothrombinase complex models differ in the orientation of FXa relative to FVa, and the binding interface between enzyme and cofactor. What is consistent between the three models is that $\mathrm{Arg}^{506}$ in FVa is occluded by the binding of FXa, rendering this site inaccessible to APC cleavage (Figure 6). Additionally $\mathrm{Arg}^{306}$ is surface exposed and not masked by FXa in any of the models. As such, the structural models suggest that this arginine site could be accessible to APC cleavage even when $\mathrm{FVa}$ or $\mathrm{FVa}_{\mathrm{i}}$ species are complexed to FXa. However, mathematical simulations allowing the cleavage to occur in FVa while bound to FXa overestimate both the rate of $\mathrm{FVa}^{\mathrm{HC}}$ disappearance and the rate of generation of $\mathrm{FVa}^{307-679 / 709}$ fragment observed empirically (data not shown). The data was best fit by modeling only the $\mathrm{FXa} \cdot \mathrm{FVa}_{\mathrm{i}}^{506}$ complex as susceptible to cleavage at $\operatorname{Arg}^{306}$. Thus the kinetic and structural modeling in concert with the empirical data suggests two effects: binding of FVa to FXa blocks both cleavage at $\mathrm{Arg}^{306}$ and $\mathrm{Arg}^{506}$ despite the unmasked surface exposure of $\mathrm{Arg}^{306}$; and that binding of $\mathrm{FXa}$ to $\mathrm{FVa}_{\mathrm{i}}^{506}$ improves the geometry at $\mathrm{Arg}^{306}$ rendering the site vulnerable to APC.

\section{APC Inactivation of Factor Va: Effect of Prothrombin}

In addition to the protection afforded to FVa by FXa in the prothrombinase complex, the substrate of the complex, prothrombin (PT), has also been shown to inhibit APC inactivation of FVa $[39,40,58]$. Guinto and Esmon reported that prothrombin protects the intact FVa molecule by competing with APC for binding to FVa [58]; more recent studies have reported a $K_{D}$ of between 500-700 nM for FVa and prothrombin $[39,40]$.

\section{Empirical Analyses}

In order to quantify the degree to which prothrombin protects FVa from APC, reactions were carried out at physiological concentrations of FVa $(20 \mathrm{nM})$ and prothrombin $(1.4 \mu \mathrm{M})$ on phospholipid vesicles $(20 \mu \mathrm{M})$. Reactions were triggered with APC (2.0 or $20.0 \mathrm{nM})$ and aliquots removed for Western blot analysis (representative blot in inset of Figure 7, Panel A). The presence of prothrombin in the system clearly protected FVa from APC inactivation by $2.0 \mathrm{nM}$ APC. After 20 minutes $35 \%$ of $\mathrm{FV}^{\mathrm{HC}}$ remained intact (Figure 7 , Panel $\mathrm{A}$, red circles), compared to less than $5 \%$ intact within 6
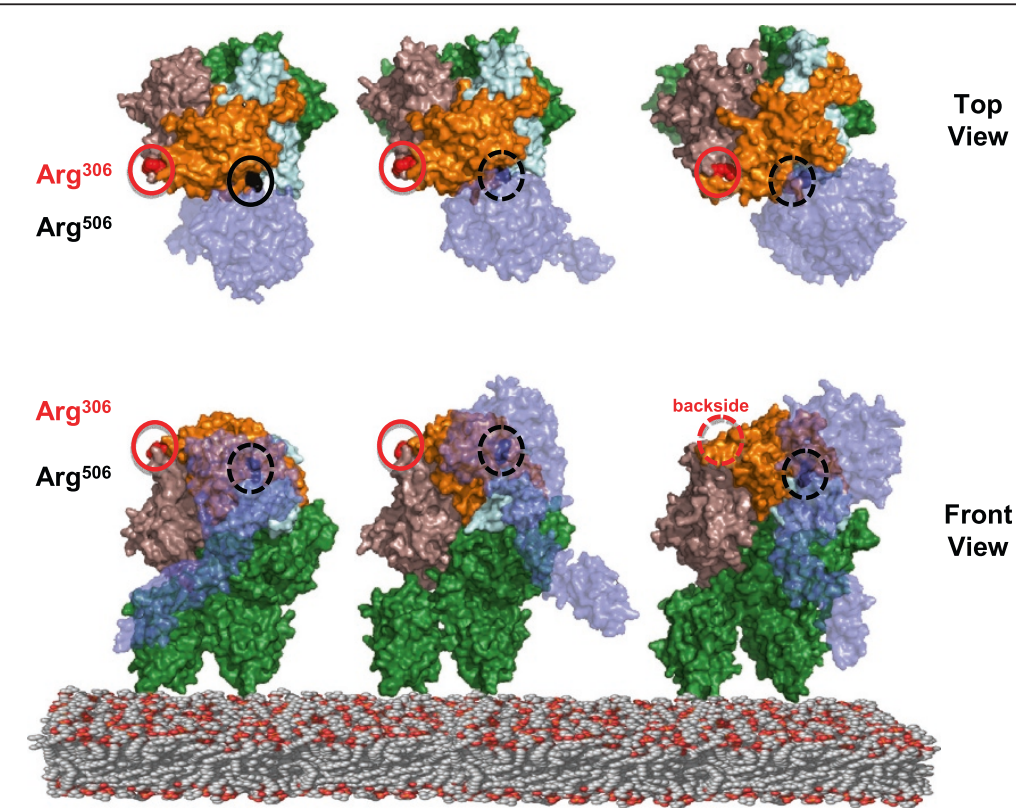

Figure 6 Structural Simulations of the Prothrombinase Complex. Top and front views of the structural simulations of the prothrombinase complex from three separate groups: Left, [52], Center [53], Right [54]. In the three models the FXa structures (presented in light blue) are based on previously solved crystal structures [PDB ID: 1XKA] [55]. In all three simulations, the FVa domain orientation is based on the crystal structure of bovine inactivated $\mathrm{FVa}_{\mathrm{i}}\left(\mathrm{FVa}^{1-306} \cdot \mathrm{FVa}^{\mathrm{LC}}\right)$ solved by Adams et al. [PDB ID: 1SDD] [56]. The FVa ${ }^{1-306}$ fragment is presented in purple, the FVa ${ }^{\mathrm{LC}}$ is presented in green, and the hypothetical structure of $\mathrm{FVa}^{307-709}$, which is based on the homology comparisons to the structure of human ceruloplasmin [PDB ID: 1KCW] [57], is presented in orange. The $\mathrm{Arg}^{306}$ residue is marked in red and encircled by a red circle and with the Arg ${ }^{506}$ residue in black and encircled by a black circle; dashed circles indicate the residue in question is completely masked by a structure from the presented view point. 


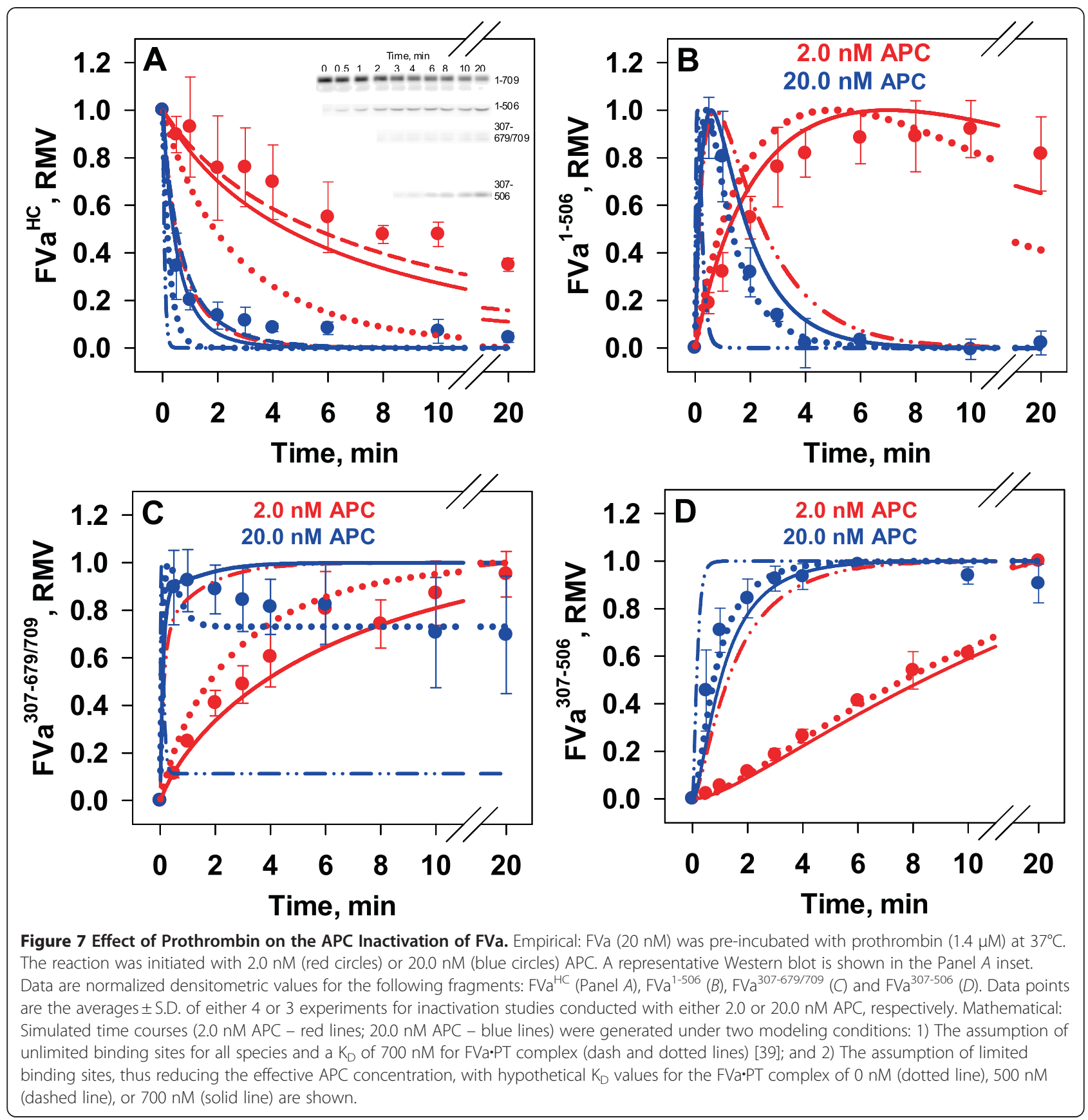

minutes in the absence of prothrombin (Figure 3, Panel $\mathrm{C}$, red circles). The initial rate of proteolysis of the heavy chain was reduced $\sim 16$-fold ( $34 \mathrm{pM} / \mathrm{s}$ vs. $558 \mathrm{pM} / \mathrm{s}$ ). The formation of the $\mathrm{FVa}^{1-506}$ fragment (Figure 7, Panel B) and rate of $\mathrm{FVa}^{307-506}$ fragment (Figure 7, Panel D) were both suppressed relative to reactions without prothrombin (Figure 3 Panels $\mathrm{D}$ and $\mathrm{E}$, respectively) suggesting both sites were protected. At $20 \mathrm{nM}$ APC (Figure 7, Panel A, blue circles) the initial rate of $\mathrm{FVa}^{\mathrm{HC}}$ proteolysis $(520 \mathrm{pM} / \mathrm{s})$ is similar to that observed with $2.0 \mathrm{nM}$ APC in the absence of prothrombin $(558 \mathrm{pM} / \mathrm{s})$.
Contrary to inactivation experiments in the absence of prothrombin (Figure 3, Panel B), there is a more noticeable generation of the $\mathrm{FVa}^{307-679 / 709}$ fragment (Figure 7, Panel A inset) that enables more reliable densitometric quantitation (Figure 7, Panel C).

\section{Mathematical Simulations}

An additional reaction describing the reversible formation of the FVa $\cdot \mathrm{PT}$ complex with a $\mathrm{K}_{\mathrm{D}}$ of $700 \mathrm{nM}$ [39] was added to the ordinary differential equation (ODE) network (Table 2, Eqn 17). The initial concentration of 
preformed $\mathrm{FVa} \cdot \mathrm{PT}$ complex, given $20 \mathrm{nM} \mathrm{FVa}$ and 1.4 $\mu \mathrm{M}$ PT, was calculated to be $13.3 \mathrm{nM}$. Simulated time courses for FVa heavy chain fragments generated by APC (2.0 nM or $20.0 \mathrm{nM}$, red and blue lines, respectively) proteolysis did not correlate well with the empirical data, in fact suggesting that there would be little to no protection of FVa by $1.4 \mu \mathrm{M}$ prothrombin if the $\mathrm{K}_{\mathrm{D}}$ was $700 \mathrm{nM}$ (Figure 7, Panel A, dashed with dotted lines vs. filled circles; Note, red dashed with dotted line is underneath blue dashed line). Test simulations varying the $K_{D}$ were performed by altering the $k_{\text {off }}$ constant for the equilibrium describing the prothrombin and FVa interaction. Even when a $K_{D}$ of $50 \mathrm{nM}$ was assigned to the interaction, $\sim 10$-fold less than published estimates [40] the resulting simulations did not capture the observed level of protection (data not shown).

In the computational model one of the assumptions is the presence of unlimited binding sites located on a single surface so that competition between proteins for occupancy of the phospholipid surface is not a factor. At 20 $\mu \mathrm{M}$ PC:PS vesicles, and setting the phospholipid/protein binding site ratio between 30 and 60 [59-61], available binding sites fall in a range between 220 and $440 \mathrm{nM}$. The simultaneous solution of the equilibrium expressions for prothrombin, FVa, and APC (defined as non-catalytic) binding to phospholipid membrane with $K_{\mathrm{D}}$ 's of $230 \mathrm{nM}$ [62], $2.72 \mathrm{nM}$ [63], and $500 \mathrm{nM}$ [64], respectively, shows that between $77-78 \%$ of binding sites are occupied by prothrombin, over $96 \%$ of the FVa is bound, and only approximately $11 \%$ of the APC is able to bind to the surface whether 2.0 or $20.0 \mathrm{nM} \mathrm{APC}$ is present. By using this bound fraction of APC as the catalytically relevant population, the mathematical simulations better captured the kinetics of $\mathrm{FV}^{\mathrm{HC}}$ proteolysis in the presence of $1.4 \mu \mathrm{M}$ prothrombin (Figure 7, Panel A, solid lines vs. filled circles). Similarly, comparison of empirical and simulated time courses for the three generated fragments (Figure 7, Panels B-D, filled circles vs. solid lines) also show improved fits. Our findings indicate that there may in fact be a tighter association between FVa and PT, in line with the findings of Yegneswaran et al. (Figure 7. Panel A, filled circles vs. dashed lines) [40].

To verify that the impaired FVa proteolysis observed under the empirical reaction conditions was not solely due to competition for phospholipid binding sites, mathematical simulations were constructed using the adjusted APC concentration, but without permitting the formation of the FVa•PT complex. This model construct failed to predict the time courses for $\mathrm{FVa}^{\mathrm{HC}}$ disappearance and the fragments $\mathrm{FVa}^{1-506}$ and $\mathrm{FVa}^{307-679 / 709}$ (Figure 7, Panel A, B and C, filled circles vs. dotted lines). Thus the computational studies indicate that the prothrombin dependent suppression of FVa proteolysis by APC observed in our empirical reactions is due both to binding site competition (prothrombin membrane association limiting APC access to the membrane surface) and to the FVa.PT complex not being a substrate for APC. Comparisons of the empirical data for $\mathrm{FVa}^{\mathrm{HC}}$ proteolysis (Figure 7, Panel A) with the simulations representing unlimited binding sites (dashed with dotted lines), limited binding site adjustment but no FVa・PT interaction (dotted line) and the limited binding site adjustment with FVa•PT complex formation $\left(K_{\mathrm{D}}=700 \mathrm{nM}\right)$ (solid line) indicate that under these conditions approximately half of the observed PT dependent suppression is due to $\mathrm{FVa} \cdot \mathrm{PT}$ complex formation.

\section{APC Inactivation of Factor Va: Effect of Prothrombin and Saturating Levels of Factor Xa Empirical Analysis}

In order to measure the cumulative protection prothrombin and saturating levels of active site blocked FXa have on the APC inactivation of FVa, reactions were carried out at physiological concentrations of FVa $(20 \mathrm{nM})$ and prothrombin $(1.4 \mu \mathrm{M})$, with saturating levels of FXa* $^{*}(30 \mathrm{nM})$ on phospholipid vesicles $(20 \mu \mathrm{M})$. Figure 8 summarizes the time course data for $\mathrm{FVa}^{\mathrm{HC}}$ proteolysis by $2.0 \mathrm{nM}$ APC for reactions constructed with FVa, FVa + $\mathrm{FXa}^{*}, \mathrm{FVa}+\mathrm{PT}$, and FVa + FXa" $+\mathrm{PT}$. The combined presence of prothrombin and $\mathrm{FXa}^{*}$ provided maximum protection against $\mathrm{APC}$ inactivation.

Figure 9 presents the empirical data comparing the proteolysis of $\mathrm{FVa}$ in the presence of $30 \mathrm{nM} \mathrm{FXa*}$ and

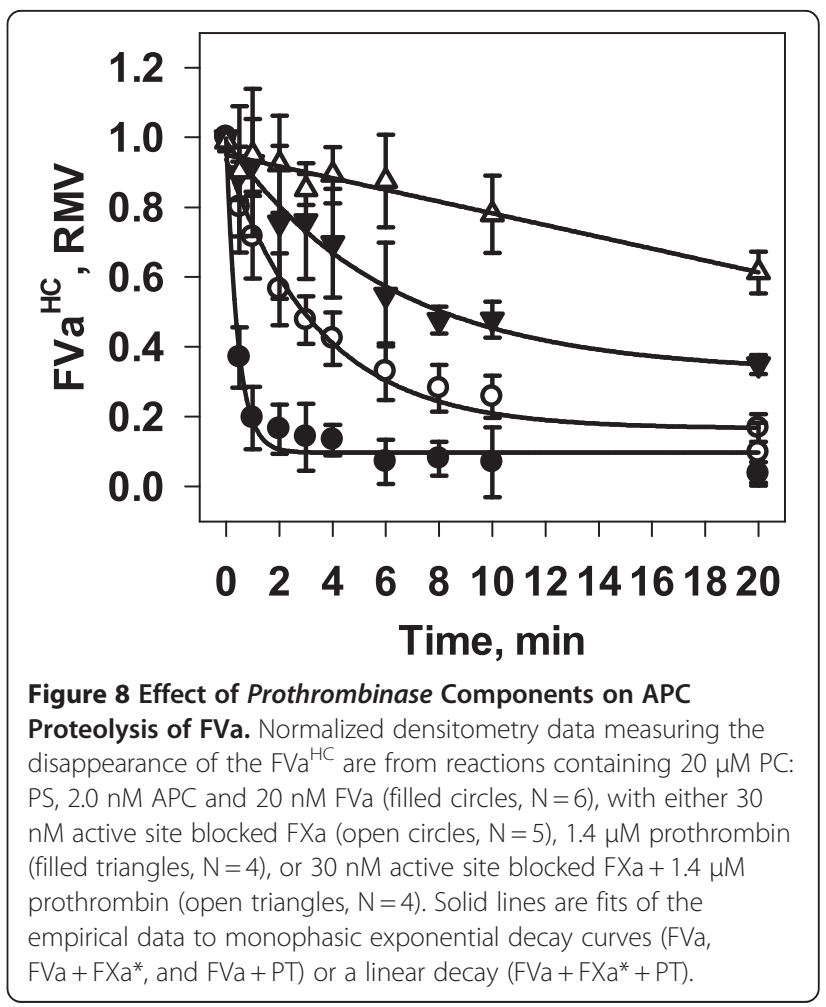


1.4 $\mu \mathrm{M}$ PT at $2.0 \mathrm{nM}$ and $20.0 \mathrm{nM}$ APC. Figure 9, Panel A shows a representative Western blot for the reactions with $2.0 \mathrm{nM}$ APC. Visual inspection of Western blots revealed extremely low generation of the inactivation fragments $\mathrm{FVa}^{1-506}, \mathrm{FVa}^{307-679 / 709}$, and $\mathrm{FVa}^{307-506}$. Productions of these fragments were consistently barely above detection limits and thus made measurement of these fragments highly variable, and as a result were not considered further.

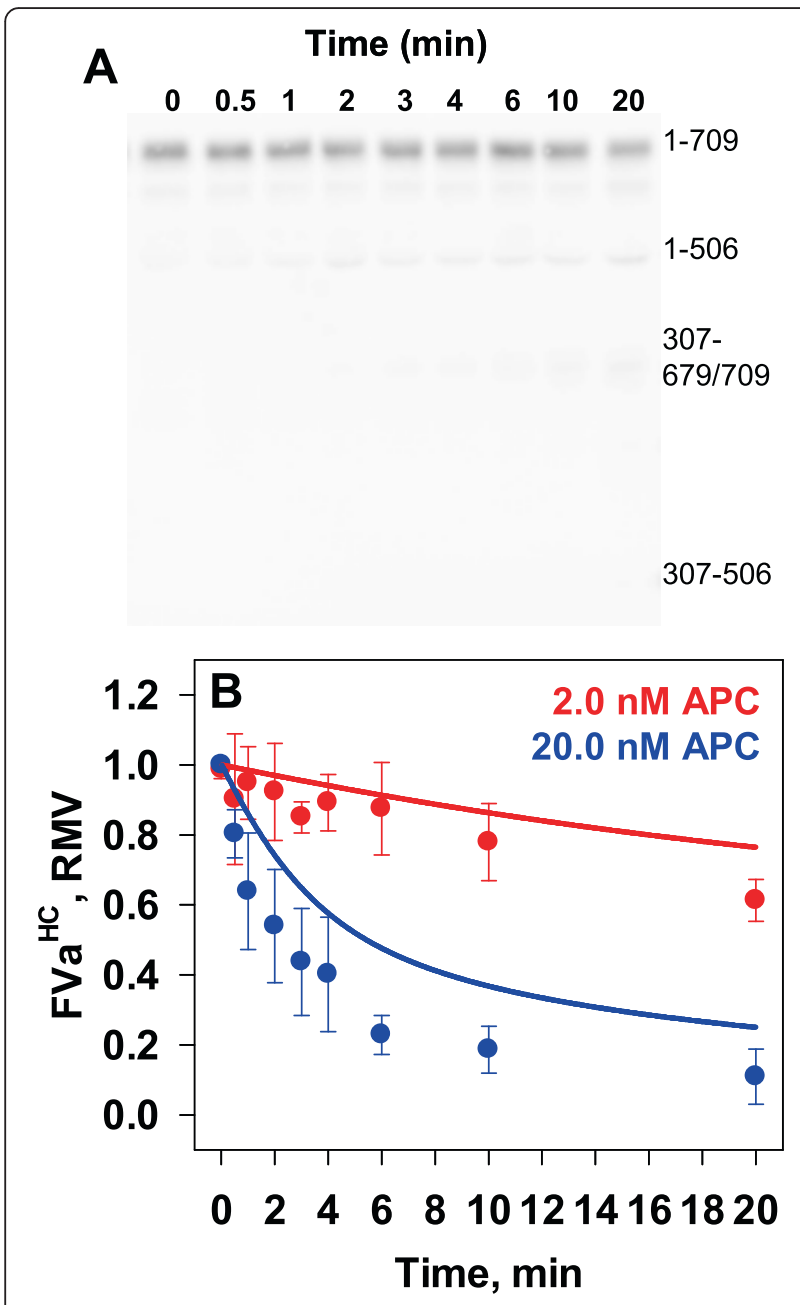

Figure 9 APC Inactivation of FVa in the Presence of Prothrombin and Saturating Levels of FXa. Empirical: FVa (20 nM) was pre-incubated with $30 \mathrm{nM}$ active site blocked FXa ( $\mathrm{FXa}^{*}$ ) and prothrombin $(1.4 \mu \mathrm{M})$ at $37^{\circ} \mathrm{C}$. The reaction was initiated with $2.0 \mathrm{nM}$ (red circles) or $20.0 \mathrm{nM}$ (blue circles) APC. A representative Western blot from an empirical experiment using $2.0 \mathrm{nM} \mathrm{APC}$ is shown in Panel $A$. Densitometric analysis of normalized measurements of the $\mathrm{FVa}^{\mathrm{HC}}$ are presented in Panel B. Data points are the averages \pm S.D. of either 4 or 3 experiments for inactivation studies conducted with either 2.0 or 20.0 nM APC, respectively. Mathematical: Simulated time courses (2.0 nM APC - red lines; $20.0 \mathrm{nM} \mathrm{APC} \mathrm{-} \mathrm{blue} \mathrm{lines)}$ were generated with the assumption of limited binding sites, resulting in an effective APC concentration of $11 \%$ (solid line) is shown.
Addition of $2.0 \mathrm{nM} \mathrm{APC}$ to the reaction system led to only $39 \%$ of the $\mathrm{FVa}^{\mathrm{HC}}$ being proteolyzed after 20 minutes (Figure 9, Panel B, red circles). The initial rate of disappearance was $14 \mathrm{pM} / \mathrm{s}$, nearly 41 -fold lower than the inactivation rate in the absence of both prothrombin and FXa (558 pM/s; Figure 3, Panel A, red circles). Inactivation studies with 10 times more APC resulted in a nearly 8 -fold increase in the initial rate of inactivation (100 pM/s) (Figure 9, Panel B, blue circles).

\section{Mathematical Simulations}

To incorporate the formation of the ternary prothrombinase substrate complex, four additional reactions are required (Table 3, Eqns 19-22). Based on studies indicating that prothrombinase complexes formed with partially proteolyzed FVa species have a $K_{M}$ similar to the complex formed with intact FVa $[31,51]$, we set the $K_{M}$ of prothrombin for any prothrombinase complex to be the same and consistent with previous modeling studies $[46,47]$. We included two additional reactions (Table 3, Eqns 23-24) to allow for the dissociation of the ternary complex formed with some of the partially proteolyzed FVa species. Solving the simultaneous equilibrium of FVa, FXa*, and PT in a lipid independent system, approximately $18.9 \mathrm{nM} \mathrm{FVa}$ is found in a prothrombinase complex (FVa $\cdot \mathrm{FXa}$ or $\mathrm{FVa} \cdot \mathrm{FXa} \cdot \mathrm{PT})$, approximately 720 $\mathrm{pM} \mathrm{FVa}$ is in the FVa $\cdot \mathrm{PT}$ complex, and approximately $360 \mathrm{pM} \mathrm{FVa}$ is unassociated.

Simulated time courses for the disappearance of the $\mathrm{FVa}^{\mathrm{HC}}$ were generated for the experiments where 2.0 $\mathrm{nM}$ or $20.0 \mathrm{nM}$ APC was added. Based on the findings from the APC inactivation studies of FVa in the presence of prothrombin, APC effective concentrations were adjusted to $11 \%$ of the total to account for the limited binding sites (Figure 9, Panel B, solid lines). The simulations' initial rates of proteolysis of the $\mathrm{FVa}^{\mathrm{HC}}(6 \mathrm{pM} / \mathrm{s})$ were less than half the measured empirical rates (14 $\mathrm{pM} / \mathrm{s})$. The mathematical simulations greater level of protection extends through 20 minutes with higher amounts of $\mathrm{FVa}^{\mathrm{HC}}$ anticipated compared to empirical results (2.0 nM APC: $76 \%$ vs. $61 \%$, respectively; 20.0 nM APC: $26 \%$ vs. $11 \%$, respectively) (Figure 9, Panel B). Empirical studies were also conducted with $50 \mu \mathrm{M}$ PC:PS vesicles and did not result in any significant changes in the initial rate or overall time course of $\mathrm{FVa}^{\mathrm{HC}}$ proteolysis by $2.0 \mathrm{nM}$ APC (data not shown), suggesting that under the current conditions, phospholipid membrane accessibility is not impeding the inactivation reaction.

Potential explanations for this disparity include: 1) accumulated effect of small errors in rate constants; 2) improved binding of APC to the surface; 3) a misestimate of the affinity of the prothrombinase prothrombin interaction; and 4) the affinity of human APC for FVa is 
Table 3 Equations describing interactions between catalytically inactive prothrombinase species and prothrombin

\begin{tabular}{|c|c|c|c|c|}
\hline Eqn & Chemical Expression & $\frac{k_{\text {off }}}{\left(s^{-1}\right)}$ & $\frac{k_{\text {on }}}{\left(M^{-1} s^{-1}\right)}$ & $\frac{k_{\text {dis }}}{\left(s^{-1}\right)}$ \\
\hline 19 & $\mathrm{FXa} \cdot \mathrm{FVa}+\mathrm{PT} \leftarrow 14-13 \rightarrow \mathrm{FXa} \cdot \mathrm{FVa} \cdot \mathrm{PT}$ & $103^{a}$ & $1.0 \times 10^{8} \mathrm{a}$ & \\
\hline 20 & $\mathrm{FXa} \cdot \mathrm{FVa}_{\mathrm{i}}^{506}+\mathrm{PT} \leftarrow 14-13 \rightarrow \mathrm{FXa}^{\circ} \cdot \mathrm{FVa}_{\mathrm{i}}^{506} \cdot \mathrm{PT}$ & 103 & $1.0 \times 10^{8}$ & \\
\hline 21 & $\mathrm{FXa} \cdot \mathrm{FVa}_{i}^{306}+\mathrm{PT} \leftarrow 14-13 \rightarrow \mathrm{FXa}^{2} \cdot \mathrm{FVa}_{i}^{306} \cdot \mathrm{PT}$ & 103 & $1.0 \times 10^{8}$ & \\
\hline 22 & $\mathrm{FXa} \cdot \mathrm{FVa}_{\mathrm{i}}^{306 / 506}+\mathrm{PT} \leftarrow 14-13 \rightarrow \mathrm{FXa} \cdot \mathrm{FVa}_{\mathrm{i}}^{306 / 506} \cdot \mathrm{PT}$ & 103 & $1.0 \times 10^{8}$ & \\
\hline 23 & $\mathrm{FXa} \cdot \mathrm{FVa}^{306} \cdot \mathrm{PT}-9 \rightarrow \mathrm{FXa}+\mathrm{FVa}^{1-306} \cdot \mathrm{FVa}^{\mathrm{LC}}+\mathrm{FVa}^{307-679 / 709}+\mathrm{PT}$ & & & 0.0035 \\
\hline 24 & $\mathrm{FXa} \cdot \mathrm{FVa}_{\mathrm{i}}^{306 / 506} \cdot \mathrm{PT}-9 \rightarrow \mathrm{FXa}+\mathrm{PT}+\mathrm{FVa}^{1-306} \cdot \mathrm{FVa}^{\mathrm{LC}}+\mathrm{FVa}^{307-506}+\mathrm{FVa}^{507-679 / 709}$ & & & 0.0035 \\
\hline
\end{tabular}

a Values from previously published studies for mathematical simulations $[32,46]$.

slightly higher, e.g. the $\mathrm{K}_{\mathrm{D}}$ is less than $7 \mathrm{nM}$. Additional experiments will be required to distinguish between these possibilities. It is important to note that phospholipid composition plays an important role in proteinmembrane interactions which can extend to effects on enzyme activity (Reviewed in [65]). Several studies have directly highlighted the effect of membrane composition on the APC inactivation of FVa [66-68].

\section{Conclusions}

We have constructed an ODE based model of APC inactivation of the prothrombinase complex. This model includes 24 chemical reactions and interactions with 14 unique rate constants which describe the flux in concentrations of 24 species (Figure 10). We did so in stepwise fashion, analyzing the time course of FVa inactivation in empirical reaction systems with increasing number of interacting components and generating corresponding model constructs of each reaction system. Reaction mechanisms, rate constants and equilibrium constants informing these model constructs were initially derived from various research groups reporting on APC inactivation of FVa in isolation [22,31-33], in the presence of FXa [14,34-38], and in the presence of prothrombin $[39,40,58]$. Model predictions were assessed against empirical time course data measuring the appearance and disappearance of multiple FVa degradation intermediates as well as prothrombinase activity changes, with experiments done multiple times, with plasma proteins derived from multiple preparations. Current coagulation models that incorporate the protein $C$ pathway [69-79] provide an often simplistic one step inactivation reaction of FVa by $\mathrm{APC}$, without incorporating the feedback inhibition of the APC $\cdot \mathrm{FVa}^{1-306} \cdot \mathrm{FVa}^{\mathrm{LC}}$ complex, the ability of partially proteolyzed FVa species to form catalytically active prothrombinase species, and the formation of $\mathrm{FVa} \cdot \mathrm{PT}$ species. They either do not provide empirical data verifying their model construct or rely on a single global output to validate the entire model construct. Wagenvoord et al. have outlined the limitations of mathematical models of complex reaction networks validated by a single analyte [80]. This study highlights the complexity of the inactivation process and is a crucial step towards creating a module of equations describing the PC pathway that can be integrated into existing comprehensive mathematical models describing the interplay between procoagulant and anticoagulant processes during tissue factor initiated coagulation.

\section{Methods}

Reagents and Proteins

Human prothrombin and Factor $\mathrm{X}$ were isolated according to methods as described [81]. Factor Xa was prepared as previously described using Russel's Viper Venom Factor Xa Activator [82,83]. Human Factor V was purified from citrated plasma according to previously described procedures [83]. Activated human protein $\mathrm{C}$ was purchased from Haematologic Technologies, Essex Junction, VT. 1,2Dioleolyl-sn-Glycero-3-Phospho-L-Serine (PS) and 1,2-Dioleoyl-sn-Glycero-3-Phosphocholine (PC) were purchased from Avanti Polar Lipids, Inc (Alabaster, AL) and phospholipid vesicles (PC:PS) composed of $75 \%$ PC and $25 \%$ PS were prepared as described $[60,84]$. Spectrozyme TH and recombinant hirudin were purchased from American Diagnostica, Inc (Greenwich, CT) and EDTA was purchased from Sigma (St Louis, MO). D-Phe-Pro-ArgCH ${ }_{2} \mathrm{Cl}$ (FPRck) was prepared in house. Monoclonal anti-fV ( $\alpha \mathrm{HFV \# 17)}$ was obtained from the Biochemistry Antibody Core Laboratory (University of Vermont) and a goat anti-mouse IgG conjugated to HRP was purchased from Southern Biotech (Birmingham, AL). Active site blocked FXa (FXa*) was produced according to the previously published method [85].

Multiple preparations of FV/FVa and different lots of APC were utilized for these studies. Preparations of Factor $\mathrm{Va}$ were made fresh prior to all experiments. Factor $\mathrm{V}$ $(1.0 \mu \mathrm{M})$ in $0.2 \mathrm{M}$ HEPES, $0.15 \mathrm{M} \mathrm{NaCl}, 0.1 \%$ PEG-8000, $2.0 \mathrm{mM} \mathrm{CaCl}_{2}$, pH 7.4 (HBS-PEG-Ca) was activated with $10 \mathrm{nM}$ human thrombin for $10 \mathrm{~min}$ at $37^{\circ} \mathrm{C}$. Thrombin activation was stopped by addition of $12 \mathrm{nM}$ recombinant hirudin and placing the sample on ice. Factor Va preparations were used within 4 hours. The partially proteolyzed species of factor Va cleaved only at $\mathrm{Arg}^{506}$ was generated by incubating FVa $(750 \mathrm{nM})$ in HBS-PEG-Ca with $5.0 \mathrm{nM}$ 


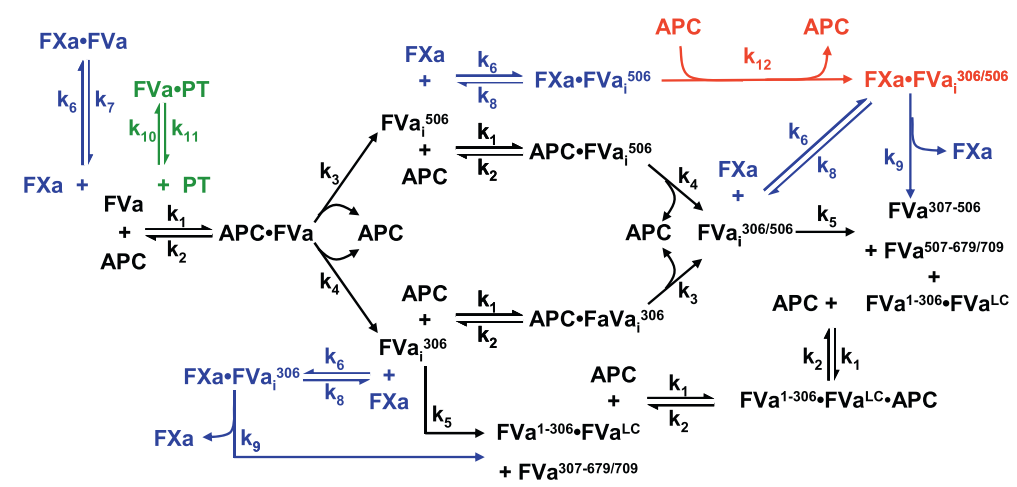

Figure 10 Reaction Scheme of APC Inactivation of FVa in the Presence of Either FXa or Prothrombin. Schematic of reactions and interactions involved in the APC inactivation of FVa when in the presence of either FXa (highlighted in blue and red) or prothrombin (highlighted in green). The interaction highlighted in red was identified in this study through the validation of the mathematical model describing the APC inactivation of FVa. Formation of the prothrombinase plus prothrombin species (Table 3, Eqns 19-22) and their dissociation (Table 3, Eqns 23-24) are not shown in this figure for clarity.

APC for 20 minutes at $37^{\circ} \mathrm{C}$, after 20 minutes an additional $5.0 \mathrm{nM}$ APC was added. Following the inactivation reaction, the $\mathrm{FVa}_{\mathrm{i}}^{506}$ containing reaction was placed on ice and incubated with $1.0 \mathrm{mM}$ di-isopropyl phosphate to inactivate the APC.

\section{Inactivation of Factor Va by Activated Protein C}

Solutions of factor Va $(20 \mathrm{nM})$ in HBS-PEG-Ca with $20 \mu \mathrm{M}$ PC:PS were prepared at $37^{\circ} \mathrm{C}$. At the zero time point 0.5 or $2.0 \mathrm{nM}$ APC was added to the FVa solution. At designated intervals samples were removed, and either quenched in denaturing sample preparation buffer (0.31 M Tris[hydroxymethyl]aminomethane, $10 \%$ sodium dodecyl sulfate, 50 \% glycerol, $0.5 \%$ Bromophenol Blue, pH 6.8) and analyzed either for proteolytic cleavage using SDS-PAGE and subsequent immunoblot analysis (Western blotting), or for co-factor activity using a onestage clotting assay in factor $\mathrm{V}$ deficient plasma. Inactivation reactions were diluted 40-fold in an appropriate volume of factor $\mathrm{V}$ deficient plasma and assayed immediately. Clotting activity is represented as a percentage of the clotting time observed for unproteolyzed FVa.

\section{Inactivation of Factor Va by Activated Protein C in the Presence of Factor Xa \\ Activity analysis:}

Rates of APC inactivation of FVa $(0.2 \mathrm{nM})$ in the presence of PC:PS vesicles $(20 \mu \mathrm{M})$ and FXa $(0.1 \mathrm{nM})$ were assessed with the prothrombinase complex preformed for five minutes at $37^{\circ} \mathrm{C}$ in HBS-PEG-Ca. At the zero time point APC (0-2.0 nM) was added to the prothrombinase complex solution. At designated intervals aliquots were removed and added to a minimal amount of concentrated prothrombin $(1.0 \mu \mathrm{M}$ final). After $90 \mathrm{~s}$, aliquots were quenched with the addition of $0.5 \mathrm{M}$ EDTA ( $25 \mathrm{mM}$ final) and subsequently monitored for thrombin activity against the chromogenic substrate SpecTH. Thrombin concentrations were determined by reference to a standard curve and the level of thrombin generated used as a relative measurement of prothrombinase concentration compared to measurements with intact FVa.

\section{Proteolytic analysis:}

Prothrombinase complex was preformed on $20 \mu \mathrm{M}$ PC: PS vesicles in HBS-PEG-Ca for four minutes at $37^{\circ} \mathrm{C}$ using $30 \mathrm{nM}$ fluorescein-active site blocked FXa (FXa*) and 20 nM FVa. A sample aliquot was removed, APC added $(2.0 \mathrm{nM})$, aliquots taken at selected time points and quenched into denaturing sample preparation buffer, and subsequently analyzed by Western blotting.

\section{Inactivation of Factor Va by Activated Protein C in the Presence of Prothrombin}

Reaction mixtures of FVa $(20 \mathrm{nM})$ and prothrombin $(1.4 \mu \mathrm{M})$ were prepared with $20 \mu \mathrm{M}$ PC:PS vesicles in HBS-PEG-Ca and incubated for four minutes at $37^{\circ} \mathrm{C}$. A sample aliquot was removed, APC added ( 2.0 or $20.0 \mathrm{nM}$ ), aliquots taken at selected time points and quenched into denaturing sample preparation buffer, and subsequently analyzed by Western blotting.

\section{Inactivation of Factor Va by Activated Protein C in the Presence of Prothrombin and Factor Xa}

Reaction mixtures of FVa $(20 \mathrm{nM})$, fluorescein-active site blocked FXa (FXa*, $30 \mathrm{nM})$, and prothrombin $(1.4 \mu \mathrm{M})$ were prepared with $20 \mu \mathrm{M}$ PC:PS vesicles in HBS-PEG-Ca and incubated for four minutes at $37^{\circ} \mathrm{C}$. A sample aliquot was removed, APC added ( 2.0 or $20.0 \mathrm{nM}$ ), aliquots taken at selected time points and quenched into denaturing sample preparation buffer, and subsequently analyzed by Western blotting. 


\section{Western blotting and densitometric analyses}

All FVa samples were run under reducing conditions. FVa heavy chain and inactivation fragments were analyzed by fractionation on 4-12 \% SDS-PAGE acrylamide slab gels followed by electrophoretic transfer of proteins to Immobilon-FL membranes (Millipore Inc., Billerica, MA), and detected using a mouse monoclonal antibody ( $\alpha \mathrm{HFV} \# 17)$ that binds to an epitope between residues 307-506 of the factor Va heavy chain and a goat anti-mouse IgG conjugated to HRP (Southern Biotech). Luminescence was detected using a Fuji LAS-4000 in conjunction with ImageCapture software (Fujifilm, Tokyo, Japan). Densitometry was carried out using MultiGauge software (Fujifilm, Tokyo, Japan). For each species, densitometric values at each time point were normalized to their maximal value during the time course.

\section{Mathematical modeling}

The description using ordinary differential equations of the reaction pathway for bovine APC inactivation of bovine FVa reported by Hockin et al. [33] was used as a starting framework (Figure 2; Table 1). The scheme describes a random order cleavage process for $\mathrm{Arg}^{306}$ and $\mathrm{Arg}^{506}$ in which the cleavages are independent of each other and characterized by substantially different rate constants. Our simulator employs a fourth order Runga-Kutta algorithm to generate a series of timedependent concentration profiles for all reactants, intermediates, and products.

Factor Va cofactor activity will be represented by the cumulative presence of $\mathrm{FVa}^{\mathrm{HC}}$ species present at any point in time. For measurements of prothrombinase activity, the sum of all FVa species was added to the weighted $(20 \%)$ sum of $\mathrm{FVa}_{\mathrm{i}}^{306}, \mathrm{FVa}_{\mathrm{i}}^{506}$, and $\mathrm{FVa}_{\mathrm{i}}^{306 / 506}$. Factor Va inactivation fragments will be represented by including respective fragments both associated and dissociated from the $\mathrm{FVa}^{\mathrm{LC}}$.

To generate an appropriate simulation of the empirical experiment where FXa and FVa are pre-incubated together on the phospholipid surface to form the prothrombinase complex prior to the addition of APC, the concentrations of free FXa and FVa, and the prothrombinase complex were solved. For example, studies with 200 pM FVa and 100 pM FXa, for each potential $K_{D}$ (e.g. $0.1 \mathrm{nM}$ or $0.5 \mathrm{nM}$, respectively), the values of the three initial conditions ranged from 41-74 pM for free FXa, 141-174 pM for free FVa, and 59$26 \mathrm{pM}$ for prothrombinase. The concentrations of the three species then served as the initial conditions in the simulations in conjunction with either APC concentration.

In silico simulations were carried out with the initial concentrations used in the empirical experiments and the relevant output calculated and compared to the appropriate analyte measured in the empirical experiments.

\section{Abbreviations}

APC: Activated protein C; EDTA: (Ethylene-dinitrilo) tetraacetic acid; FVa: Activated factor $\mathrm{V} ; \mathrm{FVa}^{\mathrm{HC}}$ : Heavy chain of FVa; FVa ${ }^{\mathrm{LC}}$ : Light chain of FVa; $\mathrm{FVa}_{\mathrm{i}}$ : A two chain molecule composed of the FVa ${ }^{\mathrm{LC}}$ and $\mathrm{FVa}^{1-306}$ fragment; FXa: Activated factor X; FXa*: Active site-blocked activated factor $X_{;}$HEPES: $\mathrm{N}$-[2-Hydroxyethyl]piperazine-N'-2-ethanesulfonic acid; HBS: 20 mM HEPES, $150 \mathrm{mM} \mathrm{NaCl}, \mathrm{pH} 7.4$; min: minutes; PC: Protein C; PC:PS vesicles: Single bilayer phospholipid vesicles composed of $75 \%$ 1,2-dioleoyl-sn-glycero-3phosphocholine and 25 \% 1,2-dioleoyl-sn-3-glycero-3-[phospho-L-serine]; PEG: Polyethylene glycol, average molecular weight = 8000; PT: Prothrombin; RMV: Relative to maximal value; s: Seconds; TF: Tissue factor.

\section{Competing interests}

Ms. Maria Cristina Bravo, Dr. Thomas Orfeo, and Dr. Stephen J. Everse declare no conflict of interest. Dr. Kenneth G. Mann is Chairman of the Board of Haematologic Technologies, Essex, VT where some of the proteins were purchased for these investigations.

\section{Acknowledgements}

This paper was supported by F31 GM 81904 (MCB), R01 HL 034575 (KGM), and P01 HL 46703 (KGM) from the National Institute of Health. Additional support was provided by contract W911NF-10-1-0376 (KGM) from the Department of Defense. Additional support was provided by NEAGEP at the University of Vermont (MCB), institutional funds from the College of Medicine at the University of Vermont (MCB), and the Department of Biochemistry at the University of Vermont (MCB, SJE).

\section{Author details}

${ }^{1}$ Cell and Molecular Biology Program, University of Vermont, 89 Beaumont Ave, Burlington VT 05405, USA. '2Department of Biochemistry, University of Vermont, 208 South Park Drive, Colchester VT 05446, USA. ${ }^{3}$ Department of Biochemistry, University of Vermont, 89 Beaumont Ave., Given B418, Burlington VT 05405, USA.

\section{Authors' contributions}

MCB designed/performed research, analyzed data and wrote the first draft of the paper. TO, KGM and SJE contributed to experimental design and to the writing of the paper. All authors read and approved the final manuscript.

Received: 15 February 2012 Accepted: 20 May 2012

Published: 20 May 2012

\section{References}

1. Esmon $C T$, Suttie JW, Jackson CM: The functional significance of vitamin $\mathrm{K}$ action. Difference in phospholipid binding between normal and abnormal prothrombin. J Biol Chem 1975, 250:4095-4099.

2. Nesheim ME, Taswell JB, Mann KG: The contribution of bovine Factor V and Factor Va to the activity of prothrombinase. J Biol Chem 1979, 254:10952-10962.

3. Rosing J, Tans G, Govers-Riemslag JW, Zwaal RF, Hemker HC: The role of phospholipids and factor $\mathrm{Va}$ in the prothrombinase complex. J Biol Chem 1980, 255:274-283.

4. Esmon CT: The subunit structure of thrombin-activated factor V. Isolation of activated factor $\mathrm{V}$, separation of subunits, and reconstitution of biological activity. J Biol Chem 1979, 254:964-973.

5. Nesheim ME, Myrmel KH, Hibbard L, Mann KG: Isolation and characterization of single chain bovine factor V. J Biol Chem 1979, 254:508-517.

6. Laki K, Gladner JA: Chemistry and Physiology of the Fibrinogen-Fibrin Transition. Physiol Rev 1964, 44:127-160.

7. Doolittle RF: Structural aspects of the fibrinogen to fibrin conversion. Adv Protein Chem 1973, 27:1-109.

8. Lorand L, Downey J, Gotoh T, Jacobsen A, Tokura S: The transpeptidase system which crosslinks fibrin by gamma-glutamyle-episilon-lysine bonds. Biochem Biophys Res Commun 1968, 31:222-230.

9. Doolittle RF, Chen R, Lau F: Hybrid fibrin: proof of the intermolecular nature of - crosslinking units. Biochem Biophys Res Commun 1971, 44:94-100.

10. Rezaie AR: Determinants of specificity of factor xa interaction with its physiological inhibitors. Mini Rev Med Chem 2006, 6:859-865. 
11. Ellis V, Scully M, MacGregor I, Kakkar V: Inhibition of human factor Xa by various plasma protease inhibitors. Biochim Biophys Acta 1982, 701:24-31.

12. Kisiel W, Canfield WM, Ericsson LH, Davie EW: Anticoagulant properties of bovine plasma protein $\mathrm{C}$ following activation by thrombin. Biochemistry 1977, 16:5824-5831.

13. Fay PJ, Smudzin TM, Walker FJ: Activated protein C-catalyzed inactivation of human factor VIII and factor VIIla. Identification of cleavage sites and correlation of proteolysis with cofactor activity. J Biol Chem 1991, 266:20139-20145.

14. Walker FJ: Regulation of activated protein $\mathrm{C}$ by protein $\mathrm{S}$. The role of phospholipid in factor Va inactivation. J Biol Chem 1981 256:11128-11131.

15. Kalafatis M, Rand MD, Mann KG: The mechanism of inactivation of human factor V and human factor Va by activated protein C. J Biol Chem 1994, 269:31869-31880

16. Esmon CT: The protein C pathway. Chest 2003, 124:26S-32S.

17. Castoldi E, Hackeng TM: Regulation of coagulation by protein S. Curr Opin Hematol 2008, 15:529-536.

18. Meijers JC, Herwald H: Protein C inhibitor. Semin Thromb Hemost 2011, 37:349-354.

19. Rezaie AR, Cooper ST, Church FC, Esmon CT: Protein C inhibitor is a potent inhibitor of the thrombin-thrombomodulin complex. J Biol Chem 1995, 270:25336-25339.

20. Esmon CT: Basic mechanisms and pathogenesis of venous thrombosis. Blood Rev 2009, 23:225-229.

21. Dahlback B, Carlsson M, Svensson PJ: Familial thrombophilia due to a previously unrecognized mechanism characterized by poor anticoagulant response to activated protein C: prediction of a cofactor to activated protein C. Proc Natl Acad Sci U S A 1993,

90:1004-1008

22. Bertina RM, Koeleman BP, Koster T, Rosendaal FR, Dirven RJ, de Ronde $H_{\text {, }}$ van der Velden PA, Reitsma PH: Mutation in blood coagulation factor $\mathrm{V}$ associated with resistance to activated protein C. Nature 1994, 369:64-67.

23. Krishnaswamy S, Williams EB, Mann KG: The binding of activated protein C to factors V and Va. J Biol Chem 1986, 261:9684-9693.

24. Yu S, Zhang L, Jhingan A, Christiansen WT, Castellino FJ: Construction, expression, and properties of a recombinant chimeric human protein $C$ with replacement of its growth factor-like domains by those of human coagulation factor IX. Biochemistry 1994, 33:823-831.

25. Mesters RM, Heeb MJ, Griffin JH: A novel exosite in the light chain of human activated protein $C$ essential for interaction with blood coagulation factor Va. Biochemistry 1993, 32:12656-12663.

26. Segers K, Dahlback B, Rosing J, Nicolaes GA: Identification of surface epitopes of human coagulation factor Va that are important for interaction with activated protein C and heparin. J Biol Chem 2008, 283:22573-22581.

27. Yegneswaran S, Kojima Y, Nguyen PM, Gale AJ, Heeb MJ, Griffin JH: Factor Va residues 311-325 represent an activated protein $C$ binding region. J Biol Chem 2007, 282:28353-28361.

28. Nicolaes GA, Bock PE, Segers K, Wildhagen KC, Dahlback B, Rosing J: Inhibition of thrombin formation by active site mutated (S360A) activated protein C. J Biol Chem 2010, 285:22890-22900.

29. Kalafatis M, Bertina RM, Rand MD, Mann KG: Characterization of the molecular defect in factor VR506Q. J Biol Chem 1995, 270:4053-4057.

30. Kalafatis M, Mann KG: Role of the membrane in the inactivation of factor Va by activated protein C. J Biol Chem 1993, 268:27246-27257.

31. Nicolaes GA, Tans G, Thomassen MC, Hemker HC, Pabinger I, Varadi K, Schwarz HP, Rosing J: Peptide bond cleavages and loss of functional activity during inactivation of factor Va and factor VaR506Q by activated protein C. J Biol Chem 1995, 270:21158-21166.

32. Mann KG, Hockin MF, Begin KJ, Kalafatis M: Activated protein C cleavage of factor Va leads to dissociation of the A2 domain. J Biol Chem 1997, 272:20678-20683.

33. Hockin MF, Cawthern KM, Kalafatis M, Mann KG: A model describing the inactivation of factor Va by APC: bond cleavage, fragment dissociation, and product inhibition. Biochemistry 1999, 38:6918-6934.

34. Kim PY, Nesheim ME: Down regulation of prothrombinase by activated protein C during prothrombin activation. Thromb Haemost 2010, 104:61-70.

35. Nesheim ME, Canfield WM, Kisiel W, Mann KG: Studies of the capacity of factor Xa to protect factor Va from inactivation by activated protein C. J Biol Chem 1982, 257:1443-1447.
36. Norstrom EA, Tran S, Steen M, Dahlback B: Effects of factor Xa and protein S on the individual activated protein C-mediated cleavages of coagulation factor Va. J Biol Chem 2006, 281:31486-31494.

37. Rosing J, Hoekema L, Nicolaes GA, Thomassen MC, Hemker HC, Varadi K, Schwarz HP, Tans G: Effects of protein S and factor Xa on peptide bond cleavages during inactivation of factor Va and factor VaR506Q by activated protein C. J Bio/ Chem 1995, 270:27852-27858.

38. Suzuki K, Stenflo J, Dahlback B, Teodorsson B: Inactivation of human coagulation factor V by activated protein C. J Biol Chem 1983, 258:1914-1920

39. Tran S, Norstrom E, Dahlback B: Effects of prothrombin on the individual activated protein C-mediated cleavages of coagulation factor Va. J Biol Chem 2008, 283:6648-6655.

40. Yegneswaran S, Nguyen PM, Gale AJ, Griffin JH: Prothrombin amino terminal region helps protect coagulation factor Va from proteolytic inactivation by activated protein C. Thromb Haemost 2009, 101:55-61.

41. Egan JO, Kalafatis M, Mann KG: The effect of Arg306-> Ala and Arg506- > Gln substitutions in the inactivation of recombinant human factor Va by activated protein C and protein S. Protein Sci 1997, 6:2016-2027.

42. Nicolaes GA, Sorensen KW, Friedrich U, Tans G, Rosing J, Autin L, Dahlback B, Villoutreix BO: Altered inactivation pathway of factor Va by activated protein C in the presence of heparin. Eur J Biochem 2004, 271:2724-2736.

43. Danforth CM, Orfeo T, Mann KG, Brummel-Ziedins KE, Everse SJ: The impact of uncertainty in a blood coagulation model. Math Med Biol 2009, 26:323-336.

44. Walker FJ, Sexton PW, Esmon CT: The inhibition of blood coagulation by activated Protein $C$ through the selective inactivation of activated Factor V. Biochim Biophys Acta 1979, 571:333-342.

45. Nesheim ME, Eid S, Mann KG: Assembly of the prothrombinase complex in the absence of prothrombin. J Biol Chem 1981, 256:9874-9882.

46. Jones KC, Mann KG: A model for the tissue factor pathway to thrombin. II. A mathematical simulation. J Biol Chem 1994, 269:23367-23373.

47. Hockin MF, Jones KC, Everse SJ, Mann KG: A model for the stoichiometric regulation of blood coagulation. J Biol Chem 2002, 277:18322-18333.

48. Krishnaswamy S, Jones KC, Mann KG: Prothrombinase complex assembly. Kinetic mechanism of enzyme assembly on phospholipid vesicles. $J$ Biol Chem 1988, 263:3823-3834.

49. Campbell JE, Brummel-Ziedins KE, Butenas S, Mann KG: Cellular regulation of blood coagulation: a model for venous stasis. Blood 2010, 116:6082-6091.

50. Odegaard B, Mann K: Proteolysis of factor Va by factor Xa and activated protein C. J Biol Chem 1987, 262:11233-11238.

51. Barhoover MA, Kalafatis M: Cleavage at both Arg306 and Arg506 is required and sufficient for timely and efficient inactivation of factor Va by activated protein C. Blood Coagul Fibrinolysis 2011, 22:317-324.

52. Everse SJ, Adams TE, Mann KG: A molecular model of the human prothrombinase complex. In Recent Advances in Thrombosis and Hemostasis. Volume 21. Edited by Tanaka K, Davie EW. Tokyo: Springer; 2008:107-132.

53. Autin L, Steen M, Dahlback B, Villoutreix BO: Proposed structural models of the prothrombinase (FXa-FVa) complex. Proteins 2006, 63:440-450.

54. Lee CJ, Lin P, Chandrasekaran V, Duke RE, Everse SJ, Perera L, Pedersen LG: Proposed structural models of human factor Va and prothrombinase. J Thromb Haemost 2008, 6:83-89.

55. Kamata K, Kawamoto H, Honma T, Iwama T, Kim SH: Structural basis for chemical inhibition of human blood coagulation factor Xa. Proc Natl Acad Sci U S A 1998, 95:6630-6635.

56. Adams TE, Hockin MF, Mann KG, Everse SJ: The crystal structure of activated protein C-inactivated bovine factor Va: Implications for cofactor function. Proc Natl Acad Sci U S A 2004, 101:8918-8923.

57. Zaitseva I, Zaitsev V, Card G, Moshkov K, Bax B, Ralph A, Lindley P: The X-ray structure of human serum ceruloplasmin at 3.1 angstrom: Nature of the copper centres. J Biol Inorg Chem 1996, 1:15-23.

58. Guinto ER, Esmon CT: Loss of prothrombin and of factor Xa-factor Va interactions upon inactivation of factor Va by activated protein C. J Biol Chem 1984, 259:13986-13992.

59. Shaw AW, Pureza VS, Sligar SG, Morrissey JH: The local phospholipid environment modulates the activation of blood clotting. J Biol Chem 2007, 282:6556-6563.

60. Higgins $D L$, Mann KG: The interaction of bovine factor $V$ and factor V-derived peptides with phospholipid vesicles. J Biol Chem 1983, 258:6503-6508. 
61. Bloom JW, Nesheim ME, Mann KG: Phospholipid-binding properties of bovine factor $V$ and factor Va. Biochemistry 1979, 18:4419-4425.

62. Lu Y, Nelsestuen GL: Dynamic features of prothrombin interaction with phospholipid vesicles of different size and composition: implications for protein-membrane contact. Biochemistry 1996, 35:8193-8200.

63. Krishnaswamy S, Mann KG: The binding of factor Va to phospholipid vesicles. J Biol Chem 1988, 263:5714-5723.

64. Smirnov MD, Safa O, Regan L, Mather T, Stearns-Kurosawa DJ, Kurosawa S, Rezaie AR, Esmon NL, Esmon CT: A chimeric protein C containing the prothrombin Gla domain exhibits increased anticoagulant activity and altered phospholipid specificity. J Biol Chem 1998, 273:9031-9040.

65. Morrissey JH, Pureza V, Davis-Harrison RL, Sligar SG, Rienstra CM, Kijac AZ, Ohkubo YZ, Tajkhorshid E: Protein-membrane interactions: blood clotting on nanoscale bilayers. J Thromb Haemost 2009, 7(Suppl 1):169-172.

66. Bakker HM, Tans G, Janssen-Claessen T, Thomassen MC, Hemker HC, Griffin $\mathrm{JH}$, Rosing J: The effect of phospholipids, calcium ions and protein $\mathrm{S}$ on rate constants of human factor Va inactivation by activated human protein C. Eur J Biochem 1992, 208:171-178.

67. Smirnov MD, Triplett DT, Comp PC, Esmon NL, Esmon CT: On the role of phosphatidylethanolamine in the inhibition of activated protein $\mathrm{C}$ activity by antiphospholipid antibodies. J Clin Invest 1995, 95:309-316.

68. Smirnov MD, Ford DA, Esmon CT, Esmon NL: The effect of membrane composition on the hemostatic balance. Biochemistry 1999, 38:3591-3598.

69. Jordan SW, Chaikof EL: Simulated surface-induced thrombin generation in a flow field. Biophys J 2011, 101:276-286.

70. Bungay SD, Gentry PA, Gentry RD: A mathematical model of lipidmediated thrombin generation. Math Med Biol 2003, 20:105-129.

71. Qiao $Y H, X u C Q$, Zeng YJ, Xu XH, Zhao H, Xu H: The kinetic model and simulation of blood coagulation-the kinetic influence of activated protein C. Med Eng Phys 2004, 26:341-347.

72. Qiao YH, Liu JL, Zeng YJ: A kinetic model for simulation of blood coagulation and inhibition in the intrinsic path. J Med Eng Technol 2005, 29:70-74.

73. Anand M, Rajagopal K, Rajagopal KR: A model for the formation, growth, and lysis of clots in quiescent plasma. A comparison between the effects of antithrombin III deficiency and protein C deficiency. J Theor Biol 2008, 253:725-738.

74. Kuharsky AL, Fogelson AL: Surface-mediated control of blood coagulation: the role of binding site densities and platelet deposition. Biophys J 2001, 80:1050-1074

75. Fogelson AL, Tania N: Coagulation under flow: the influence of flowmediated transport on the initiation and inhibition of coagulation. Pathophysiol Haemost Thromb 2005, 34:91-108.

76. Ermakova EA, Panteleev MA, Shnol EE: Blood coagulation and propagation of autowaves in flow. Pathophysiol Haemost Thromb 2005, 34:135-142.

77. Kastrup CJ, Shen F, Runyon MK, Ismagilov RF: Characterization of the threshold response of initiation of blood clotting to stimulus patch size. Biophys J 2007, 93:2969-2977.

78. Panteleev MA, Ovanesov MV, Kireev DA, Shibeko AM, Sinauridze El, Ananyeva NM, Butylin AA, Saenko EL, Ataullakhanov Fl: Spatial propagation and localization of blood coagulation are regulated by intrinsic and protein C pathways, respectively. Biophys J 2006, 90:1489-1500.

79. Luan D, Zai M, Varner JD: Computationally derived points of fragility of a human cascade are consistent with current therapeutic strategies. PLoS Comput Biol 2007, 3:e142.

80. Wagenvoord R, Hemker PW, Hemker HC: The limits of simulation of the clotting system. J Thromb Haemost 2006, 4:1331-1338.

81. Bajaj SP, Mann KG: Simultaneous purification of bovine prothrombin and factor X. Activation of prothrombin by trypsin-activated factor X. J Biol Chem 1973, 248:7729-7741.

82. Krishnaswamy S, Church WR, Nesheim ME, Mann KG: Activation of human prothrombin by human prothrombinase. Influence of factor Va on the reaction mechanism. J Biol Chem 1987, 262:3291-3299.

83. Katzmann JA, Nesheim ME, Hibbard LS, Mann KG: Isolation of functional human coagulation factor $\mathrm{V}$ by using a hybridoma antibody. Proc Natl Acad Sci U S A 1981, 78:162-166.

84. Barenholz Y, Gibbes D, Litman BJ, Goll J, Thompson TE, Carlson RD: A simple method for the preparation of homogeneous phospholipid vesicles. Biochemistry 1977, 16:2806-2810.
85. Pryzdial EL, Mann KG: The association of coagulation factor Xa and factor Va. J Biol Chem 1991, 266:8969-8977.

doi:10.1186/1752-0509-6-45

Cite this article as: Bravo et al:: Modeling of human factor Va

inactivation by activated protein C. BMC Systems Biology 2012 6:45.

\section{Submit your next manuscript to BioMed Central and take full advantage of:}

- Convenient online submission

- Thorough peer review

- No space constraints or color figure charges

- Immediate publication on acceptance

- Inclusion in PubMed, CAS, Scopus and Google Scholar

- Research which is freely available for redistribution 